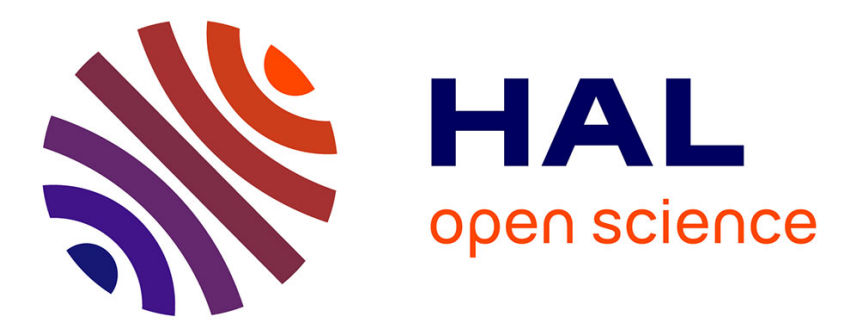

\title{
Synthetic strategy studies for a concise access to functionalized pyrano[4,3-b]pyridin-7-ones: An entry to semi-rigid analogs of antihistamines
}

Anissa Beghennou, Kevin Passador, Anthony Passador, Vincent Corcé, Serge Thorimbert, Candice Botuha

\section{To cite this version:}

Anissa Beghennou, Kevin Passador, Anthony Passador, Vincent Corcé, Serge Thorimbert, et al.. Synthetic strategy studies for a concise access to functionalized pyrano[4,3-b]pyridin-7-ones: An entry to semi-rigid analogs of antihistamines. European Journal of Organic Chemistry, 2020, 2020 (36), pp.5880-5889. 10.1002/ejoc.202001016 . hal-02990214

\section{HAL Id: hal-02990214 https://hal.sorbonne-universite.fr/hal-02990214}

Submitted on 9 Dec 2020

HAL is a multi-disciplinary open access archive for the deposit and dissemination of scientific research documents, whether they are published or not. The documents may come from teaching and research institutions in France or abroad, or from public or private research centers.
L'archive ouverte pluridisciplinaire HAL, est destinée au dépôt et à la diffusion de documents scientifiques de niveau recherche, publiés ou non, émanant des établissements d'enseignement et de recherche français ou étrangers, des laboratoires publics ou privés. 


\title{
Synthetic strategy studies for a concise access to functionalized pyrano[4,3-b]pyridin-7-ones: An entry to semi-rigid analogs of antihistamines
}

\author{
Anissa Beghennou, ${ }^{[\mathrm{a}]}$ Kevin Passador, ${ }^{[\mathrm{a}]}$ Anthony Passador, ${ }^{[\mathrm{a}]}$ Vincent Corcé, ${ }^{[\mathrm{a}]}$ Serge Thorimbert ${ }^{[\mathrm{a}]}$ and \\ Candice Botuha ${ }^{*}[a]$
}
[a] Ms Anissa Beghennou, Dr Kevin Passador, Mr Anthony Passador, Dr Vincent Corcé, Pr Serge Thorimbert and Dr Candice Botuha, Institut Parisien de Chimie Moléculaire, Sorbonne Université, CNRS, 4 place Jussieu, 75005 Paris, France
*Corresponding author Dr Candice Botuha (Email: candice.botuha@sorbonne-universite.fr) Web: http://www.ipcm.fr/article147.html

\begin{abstract}
We report short and efficient syntheses of polyfunctionalized 5,8-dihydro-7H-pyrano[4,3-b]pyridin-7-ones and 1,4-dihydro-3H-pyrano[4,3-c]pyridin-3-ones which can be considered as new aza analogs of 3 -isochromanones and as promising scaffolds for medicinal chemistry. Depending on the nature of the substituent, three different and complementary synthetic methodologies were used allowing the introduction of significant diversity in the substituent on the lactone ring of the pyranopyridinones. The selective $\alpha$-arylation of nitrile $\left(S_{N} A r\right)$ and tert-butylester enolate (Pd catalyzed) followed by an acidic mediated lactonisation gives access to original C8-functionalized pyrano[4,3-b] pyridin-7-ones and a seleno-mediated cyclization to C1functionalized pyrano[4,3-c]pyridin-3-ones. We have also applied the outlined synthetic methodologies to the preparation of potential semi-rigid analogs of antihistamines.
\end{abstract}

\section{Introduction}

3-isochromanones and derivatives belong to an important class of heterocycle compounds found in several natural products or as useful building blocks to access biological active compounds. ${ }^{[1]}$ Among them, aza analogs of 3-isochromanones or pyranopyridin ones derivatives containing a pyridine ring instead of a phenyl ring are less known heterocycles despite some promising results obtained as medicinal compounds (Figure 1). ${ }^{[2]}$ Efforts have been dedicated to the development of efficient syntheses of 3 isochromanones. ${ }^{[3]}$ However, limited synthetic procedures for the preparation of aza 3 -isochromanones analogs are reported. ${ }^{[4]}$ The main synthetic approaches to the construction of the delta lactone ring of 3-isochromanones are based on sigmatropic rearrangement on benzocyclobutenes, on ynamide or Baeyer Villiger oxidation on benzocyclopentanones. ${ }^{[3 \mathrm{bdk}]}$ These approaches are hardly appropriate to the preparation of pyranopyridinones because pyridine based starting material required in these strategies are not as accessible as their benzo analogs.

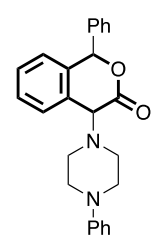

antihistamines

$\mathrm{F}_{3} \mathrm{C}$

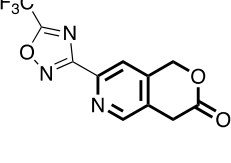

Fungicide

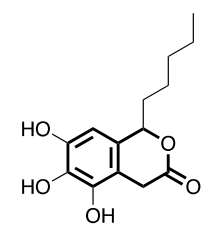

AKT2 enzyme inhibitor

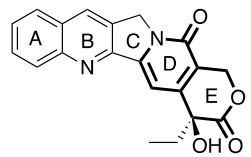

DE Ring analogs of camptothecin (anti-topoisomerase)
Figure 1. Example of molecules containing (aza) 3-isochromanone scaffold with biological interest.

Among the four possible isomers of pyranopyridinones, three of them, namely PP1 (N1) ${ }^{[4 a b c]}$, PP3 (N3) ${ }^{[4 \mathrm{de}]}$ and PP4 (N4) $)^{[4]]}$, have been described in the literature, albeit with a narrow range of substituent (Scheme 1). However, the employed strategies narrow the introduction of structural diversity on the lactone ring, a major drawback for potential use in medicinal chemistry. Finally, the lack of effective strategies to access these useful polyfunctionalized lactones makes them still under-explored.

Herein, we present a significant improvement in the synthesis of pyranopyridinones using three different but complementary synthetic methodologies allowing for the first time to easily access polyfunctionalized 5,8-dihydro-7H-Pyrano[4,3-b]pyridin-7-ones PP1 and in particular 1,4-dihydro-3H-Pyrano[4,3-c]pyridin-3-ones PP2 for which no synthesis has been reported yet. We report an optimized synthetic procedure for selective monoarylation-nucleophilic substitution of tert-butylester enolate and $\alpha$-arylation of various het(aryl)acetonitriles with ortho-substituted chloropyridine followed by acidic mediated lactonisation. We described also an original seleno-mediated cyclization on pyridyl substituted alkynol allowing to construct substituted pyridine fused delta-lactones with efficiency. In the second part of this article, we describe the preparation of original potential semi-rigid analogs of antihistamines using the outlined synthetic methodologies. 


\section{Results and Discussion}

Unsubstituted PP1 was first synthesized in 1957 by Bohlmann and coll. from ethyl-2-methyl-pyridine-3-carboxylic acid in two steps via a cyclocondensation of dilithiated intermediate. ${ }^{[4 a]}$ Then, in 1991, Alm and coll. reported the synthesis of a polyhydroxylated pyridolactone using a $[2+2+2]$ cobalto-catalyzed cycloaddition in $9 \%$ global yield with no functionalization of the lactone ring. ${ }^{[4 b]}$ Our first approach to functionalized pyranopyridinone PP1 takes advantage of a Buchwald type pallado-catalyzed $\alpha$-arylation of tert-butyl acetate ester with a TBS protected chloropyridine (method A, Scheme 1). ${ }^{[5]}$ We prepared the required trimethylsilyl protected (2-chloropyridin-3yl)- methanol 3 from commercially available 2-chloropyridine-3carboxaldehyde 1 by reduction with sodium borohydride followed by hydroxyl group protection with tert-butyltrimethylsilyl chloride (Scheme 2) ${ }^{[6]}$
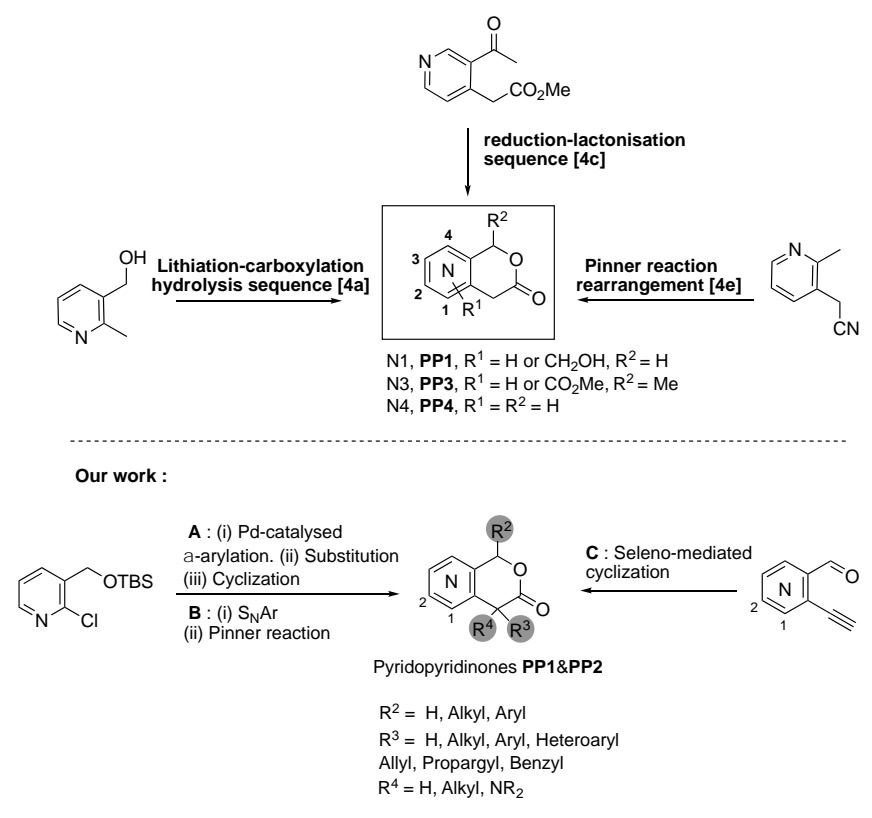

Scheme 1. Main synthetic strategies for pyranopyridinones and our approaches

The selective monoarylation reaction of tert-butyl acetate with 3 was achieved with tert-BuXphosPdCl (1 mol\%) as a pre-catalyst and LiHMDS as a base in toluene. The reaction was run at $0^{\circ} \mathrm{C}$ to prevent the potential formation of bis-arylated by-product. The reaction reached $86 \%$ conversion by adding $2 \mathrm{~mol} \%$ of the precatalyst. In our preliminary studies when ethyl acetate was employed instead of tert-butyl acetate, less than $30 \%$ conversion was observed However, under these conditions the same $\alpha$-arylation using substituted esters was not productive. The presence of an $\alpha$ substituent on the enolate generally leads to the instability of alkali ester enolates or the formation of bis-arylated products. ${ }^{[5 b]}$ The use of substituted zinc enolate esters could be required. Besides, such arylation reactions are subsequently substrate-dependent and limited to a small range of substrate. ${ }^{[7]}$ We introduce various substituent such as alkyl/ benzylic/ allylic and propargyl groups on pyrido ester $\mathbf{4}$ by a deprotonation/ nucleophilic substitution sequence. After optimization, this transformation was achieved successfully by using LiHMDS as a base and a slight excess of the corresponding halide compound as the electrophile. The expected substituted pyridoesters $\mathbf{5}$ with alkyl, allyl, benzyl and propargyl substituent were thus obtained with yields up to $89 \%$.

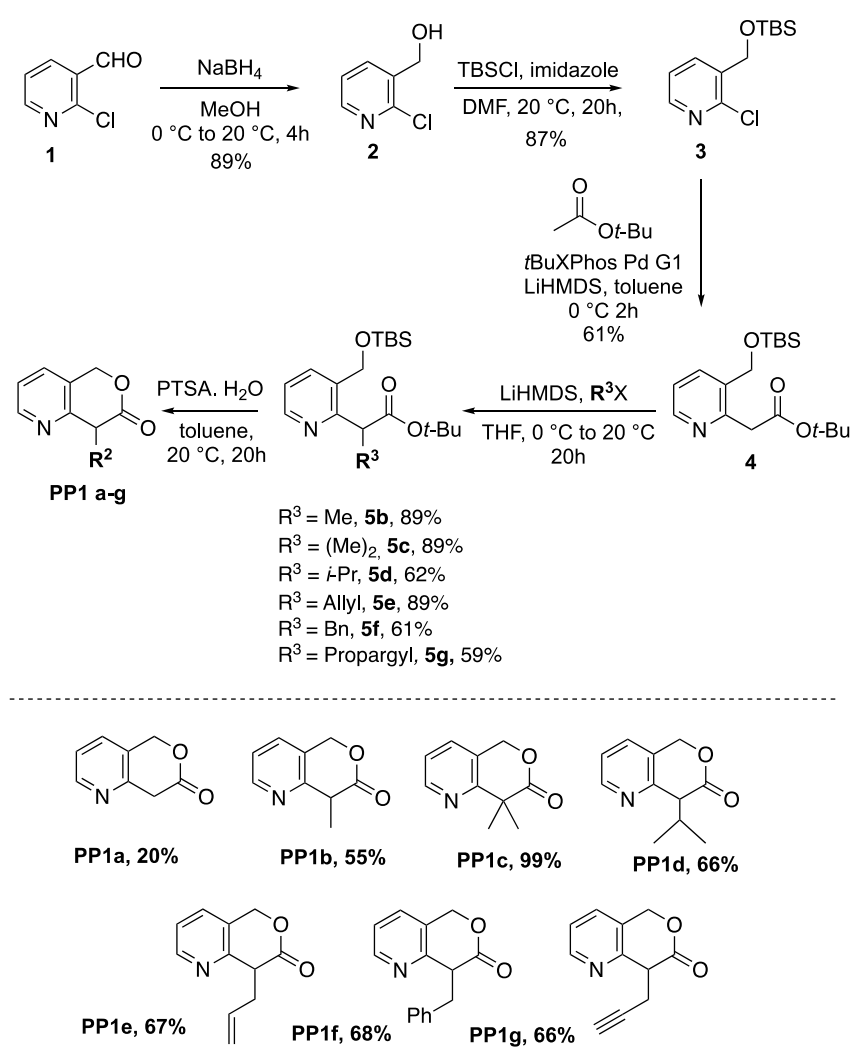

Scheme 2. Synthesis of alkyl substituted pyranopyridinones PP1a-g following $\operatorname{method} A$

The pyranopyridinones PP1a-g are easily obtained from $\mathbf{5}$ by an acidic deprotection followed by a lactonisation using 4 eq. of PTSA monohydrate. The unsubstituted pyranopyridinone PP1a was obtained in $20 \%$ isolated yield whereas substituted pyranopyridinones PP1b-g were isolated for the first time in yield from 55\% to $99 \%$ for gem-dimethyl PP1c benefiting from Thorpe Ingold effect for cyclization. ${ }^{[8]}$

We examined a strategy based on the Pinner reaction (method B, Scheme 1) to introduce aromatic substituent on the methylene group of the pyridine ester 4 . It requires the preparation of nitrile analogs of compounds $\mathbf{5}$ via nucleophilic aromatic substitution of a chloropyridine (Scheme 2 and Scheme 3). ${ }^{[9]}$

The aryl-substituted 2-pyridyl acetonitrile precursors 7a-e were prepared from the protected 2-chloropyridine $\mathbf{3}$ and the corresponding aryl or heteroaryl acetonitrile.

We first studied the substitution step by using phenylacetonitrile as a model nucleophile (Table 1$){ }^{[10]}$ When treated with 3 equivalents of LiHMDS in the presence of 2 equivalents of phenylacetonitrile in toluene at room temperature, the chloropyridine $\mathbf{3}$ gave the expected $\mathrm{S}_{N} \operatorname{Ar}$ product $7 \mathrm{a}$ in a $62 \%$ isolated yield (Table 1 entry 1 ). However, these conditions were ineffective when using other substituted arylacetonitriles.

Among the few modifications screened (solvent, base, temperature) to improve the yield, the reaction time and the scope of the $S_{N} A r$ reaction, the use of a large excess of $\mathrm{NaH}$ in $\mathrm{THF}$ at $70{ }^{\circ} \mathrm{C}$ was found to be the best reaction conditions allowing us to isolate the expected $S_{N} A r$ product with an optimized yield of $69 \%$ (Table 1, entry 5 ). Interestingly, this protocol (2 equiv. of phenylacetonitrile in 
the presence of 5 equiv. of $\mathrm{NaH}$ in THF at reflux $3 \mathrm{~h}$ ), was successively extended to other (Het)arylacetonitrile compounds giving the corresponding $S_{N} A r$ product with yields ranging from 56 to $74 \%$ (Scheme 3). The nucleophilic substitution was also performed on the more hindered phenyl substituted chloropyridine 6 giving the expected product $7 \mathrm{e}$ as a $3 / 1$ mixture of diastereoisomers (Scheme $3)$.

Table 1. Optimization table for nucleophilic substitution of $\mathbf{3}$

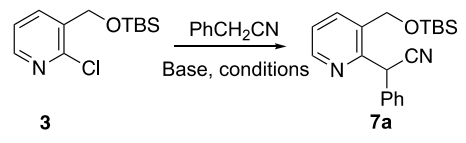

\begin{tabular}{ccll}
\hline Entry & \multicolumn{1}{c}{ Base } & Conditions & $\begin{array}{c}\text { Yield } \\
(\%)^{[\mathrm{a}]}\end{array}$ \\
\hline 1 & LiHMDS (3 equiv.) & Toluene, 0 ${ }^{\circ} \mathrm{C}$ to rt, 24h & 62 \\
2 & $\mathrm{NaNH}_{2}$ (4 equiv.) & Toluene, rt, 24h & 20 \\
3 & tBuOK (3 equiv.) & NMP, 110 ${ }^{\circ} \mathrm{C}$ & _[b] \\
4 & $\mathrm{NaH}$ (2 equiv.) & THF, reflux, 2h & 59 \\
5 & $\mathrm{NaH}$ (5 equiv.) & THF, reflux, 3h & 69 \\
\hline
\end{tabular}

[a] Isolated yield. [b] The expected product was not observed only starting material was recovered.

The intramolecular Pinner reaction (PTSA monohydrate at reflux in toluene) was run on five aryl-substituted 2-pyridyl acetonitrile compounds $7 \mathrm{a}-\mathrm{e}$, affording the desired lactones in 39 to $71 \%$ isolated yields. Unfortunately, under these acidic conditions a competitive decyanation of the dipyridyl substituted acetonitrile $\mathbf{7 d}$ was observed during the reaction. It is proposed that, under acidic conditions, the protonated electron withdrawing 2-pyridyl substituents activates the benzylic position leading preferentially to decyanation over cyclization.

The high reactivity of the 2-position of the pyridine ring on protected 2-chloropyridylethanol $\mathbf{3}$ allowed an effective introduction of various substituents on pyranopyridinone PP1 using $S_{N} A r$ approach.

$$
\begin{aligned}
& \text { OTBS } \\
& \begin{array}{ll}
\mathrm{R}^{1}=\mathrm{H}, \mathbf{3} & \\
\mathrm{R}^{1}=\mathrm{Ph}, \mathbf{6} & \mathrm{R}^{1}=\mathrm{H}, \mathrm{R}^{3}=\mathrm{Ph}, \mathbf{7 a}, 69 \% \\
& \mathrm{R}^{1}=\mathrm{H}, \mathrm{R}^{3}=4-\mathrm{Br}-\mathrm{Ph}, \mathbf{7 b},
\end{array} \\
& \mathrm{R}^{1}=\mathrm{H}, \mathrm{R}^{3}=4-\mathrm{Br}-\mathrm{Ph}, 7 \mathbf{b}, 63 \% \\
& \mathrm{R}^{1}=\mathrm{H}, \mathrm{R}^{3}=4-\mathrm{OMe}-\mathrm{Ph}, 7 \mathrm{c}, 74 \% \\
& R^{1}=H, R^{3}=2-P y r, 7 d, 56 \% \text { (crude) } \\
& \mathrm{R}^{1}=\mathrm{R}^{3}=\mathrm{Ph}, 7 \mathrm{e}, 30 \%(\mathrm{dr}: 3 / 1)
\end{aligned}
$$

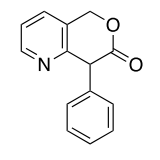

PP1h, 55\%

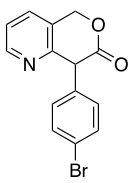

PP1i, 71\%

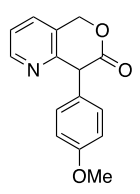

PP1j, 36\%

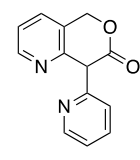

PP1k, 0\%

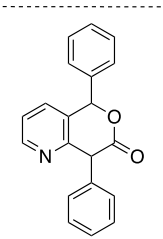

PP11, 76\% (dr : 3/1)
Scheme 3. Synthesis of aryl substituted pyranopyridinones PP1h-I via method

Original functionalized pyranopyridinones PP2 possessing the nitrogen atom at the 3 position of the pyridyl ring were prepared following an unreported selenium-promoted ring closure reaction using pyridoalkynols (Scheme 4). We based our approach on the work of Tiecco et al. ${ }^{[11]}$ who described the conversion of hydroxyl alkynyl phenyl selenides into delta-lactones through proton-induced ring-closure reaction. However, there are limited examples of deltalactones synthesized using this methodology with only one example of a benzofused lactone and no example containing a heteroaromatic ring. We thus first investigated the possible conversion of alkynylpyridyl derivatives into pyranopyridinones PP1 and PP2 using this seleno mediated cyclization. The alkynyl pyridyl carboxaldehydes $\mathbf{8}$ and $\mathbf{9}$ were synthesized with good yields from the corresponding bromopyridine derivatives via the Sonogashira reaction using an improved procedure. The best conditions were using $\mathrm{Pd}(\mathrm{Cl})_{2}\left(\mathrm{PPh}_{3}\right)_{2}$ and Cul as catalysts, DABCO as a base instead of $\mathrm{Et}_{3} \mathrm{~N}$ (Scheme 4). ${ }^{[12]}$ The alkynyl deprotection was carried out with potassium carbonate in methanol in $5 \mathrm{~min}$ affording the expected alkynyl pyridyl carboxaldehyde $\mathbf{1 0}$ and $\mathbf{1 1}$ in $95 \%$ and $89 \%$ yield respectively.
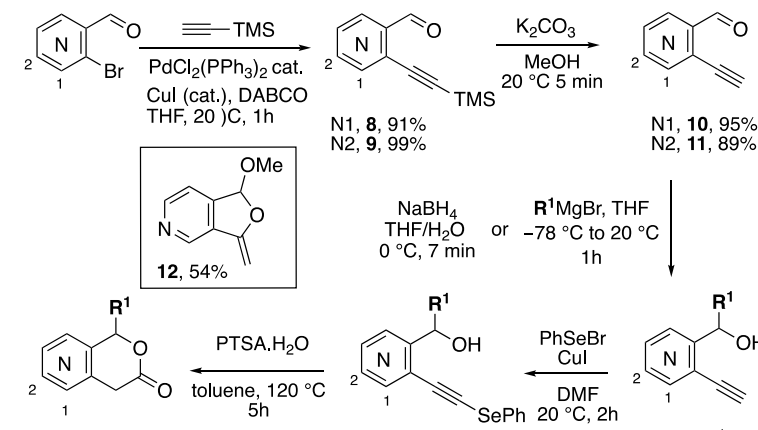

PP1a and PP2a-c

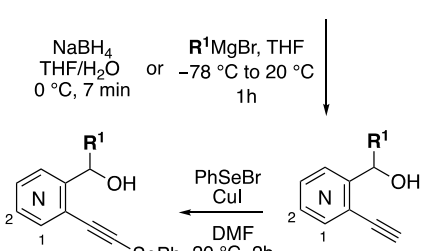

$\mathrm{N} 1,17, \mathrm{R}^{1}=\mathrm{H} \quad 74 \%$
$\mathrm{~N} 2,18, \mathrm{R}^{1}=\mathrm{H} 78 \%$
$\mathrm{~N} 2,19, \mathrm{R}^{1}=\mathrm{Me} 73 \%$ N2, 19, R $\mathrm{R}^{1}=$ Me $73 \%$
N2, 20, R $1=$ Ph $53 \%$ $\mathrm{N} 1, \mathbf{1 3}, \mathrm{R}^{1}=\mathrm{H} \quad 73 \%$
$\mathrm{~N} 2,14, \mathrm{R}^{1}=\mathrm{H} \quad 89 \%$ $\mathrm{N} 2,15, \mathrm{R}^{1}=\mathrm{Me} 54 \%$ $\mathrm{N} 2,16 \mathrm{R}^{1}=\mathrm{Ph} 62 \%$

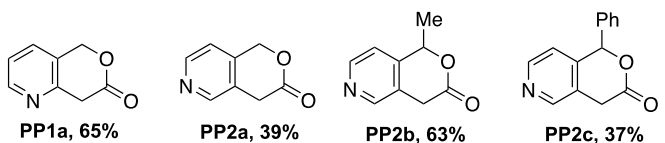

Scheme 4. Synthesis of pyranopyridinones PP1a and PP2a-c via method C

Interestingly, when the TMS deprotection was run for longer reaction time, the furo[3,4,c]pyridine 12 was isolated in $54 \%$ yield resulting from an intramolecular 5-exo-dig cyclization (Scheme 4).

Reduction of the carbonyl function with $\mathrm{NaBH}_{4}$ in a mixture of THF/ $\mathrm{H}_{2} \mathrm{O}$ was performed on both regioisomers 10 and 11 giving the corresponding alkynols $\mathbf{1 3}$ and $\mathbf{1 4}$ in good yields. In parallel, methyl and phenyl substituted-alkynols 15 and 16 were obtained successfully by the reaction of $\mathbf{1 0}$ or $\mathbf{1 1}$ with the corresponding Grignard reagent (Scheme 4). The alkynyl pyridyl selenides 17-20 were prepared from the corresponding alkynols 13-16 with phenylselenyl bromide and two equivalent of copper iodide. ${ }^{[13]}$ Finally, the reaction of selenides 17-20 with an excess of PTSA monohydrate proceeds smoothly in toluene at $120^{\circ} \mathrm{C}$ in $5 \mathrm{~h}$ to give selectively pyranopyridinones PP1a and substituted PP2 a-c in moderate yield (Scheme 4).

Thus, we have developed a rapid access to diverse isomers of functionalized pyranopyridinones using three complementary strategies. To increase substituent diversity on pyranopyridinones, we have investigated the synthesis of a new class of semi-rigid compounds based on pyranopyridinones scaffolds with potentially interesting properties as an antifungal, enzyme inhibitors or 
antihistaminics. The latter are therapeutics targeting the histamine receptors ( $\mathrm{H} 1 \mathrm{R}$ to $\mathrm{H} 4 \mathrm{R})$ involved in the regulation of many aspects of diseases such as allergic rhinitis, autoimmune diseases and infection. ${ }^{[14]}$ Among these therapeutic agents, antihistamines $\mathrm{H} 1$ have long been employed to treat allergy.
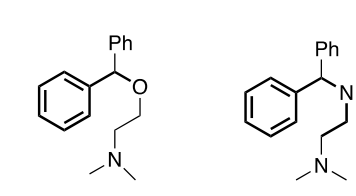

Diphenylhydramine

Phenbenzamine

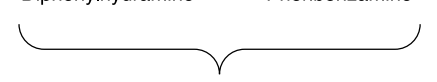

Commercially available flexible antihistamines

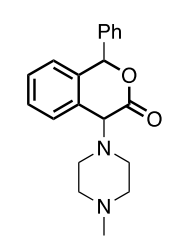

Isochromanone

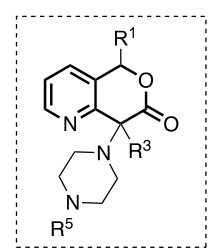

Pyranopyridinones

Figure 2. New class of potential semi-rigid antihistamines based on pyranopyridinones scaffold

First and second generations of $\mathrm{H} 1$-antihistamines are commonly flexible molecules possessing a diarylmethane moiety i.e. phenbenzamine, cetirizine, doxylamine (Figure 2). ${ }^{[15]}$ However, rotationally constrained molecules of these types are highly desired in order to get more insight to identify the active conformation of histamine itself and thus get more selective $\mathrm{H} 1$-receptor antagonists. $^{[16]}$ Semi-rigid piperazine substituted 3-isochromones have proved earlier to possess significant antihistaminic activity $(\mathrm{H} 1)$ in isolated guinea pig opening the way to develop other semi-rigid molecules with increased antihistaminic properties through structureactivity relationship studies. ${ }^{[16]}$

In first instance, we have investigated the synthesis of piperazinyl substituted pyranopyridinones, as starting point to develop other original aza analogs of semi-rigid antihistamines described above. PP1a and PP1h were converted into the corresponding bromopyranopyridinones PP1m $\left(R^{3}=H, R^{4}=B r\right)$ and PP1n $\left(R^{3}=\right.$ $\mathrm{Ph}, \mathrm{R}^{4}=\mathrm{Br}$ ) by reaction with 1 equivalent of $\mathrm{N}$-bromosuccinimide. The title compounds PP1o, PP1p and PP1q were then synthesized in yields up to $71 \%$ by condensation of amines such as $\mathrm{N}$-methyland $N$-phenyl piperazine in the presence of trimethylamine or potassium carbonate (Scheme 5 ).

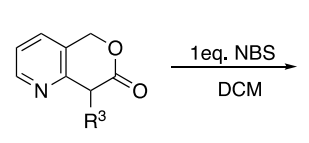
$\mathrm{R}^{3}=\mathrm{H}, \mathrm{PP} 1 \mathrm{a}$
$\mathrm{R}^{3}=\mathrm{Ph}, \mathrm{PP} 1 \mathrm{~h}$ $R^{3}=H, P P 1 m, 59 \%$
$R^{3}=P h, P P 1 n, 80 \%$
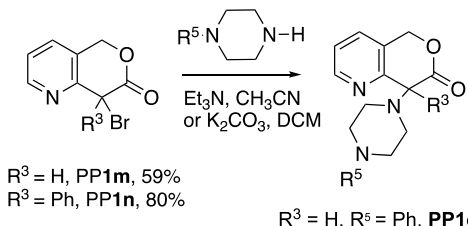

$R^{3}=H, R^{5}=P h, P P 10,22 \%$ $\mathrm{R}^{3}=\mathrm{Ph}, \mathrm{R}^{5}=\mathrm{Ph}, \mathrm{PP} 1 \mathrm{p}, 71 \%$ $\mathrm{R}^{3}=\mathrm{Ph}, \mathrm{R}^{5}=\mathrm{Me}, \mathrm{PP} 1 \mathrm{q}, 62 \%$

Scheme 5. A new class of potential analogs of anti-histamines

\section{Conclusion}

In conclusion, two isomers of functionalized pyranopyridinones were synthesized using three different and complementary synthetic methodologies allowing the introduction of various substituents on the lactone ring. We also applied the outlined synthetic methodologies to prepare semi-rigid analogs of antihistamines with potential biological importance opening the way to develop a new generation of anti-histamines with increased properties. For a future structure-activity relationship studies, other substitution and structural modifications of pyranopyridinones are highly needed and could be easily envisioned based on our developed methodology. The scope of the reaction as well as biological evaluation of these compounds on $\mathrm{H} 1$ receptors are underway in the laboratory and will be reported in due course.

\section{Experimental Section}

General: NMR spectra were recorded on Bruker Avance III $300 \mathrm{MHz}$ or $400 \mathrm{MHz}$ spectrometers at room temperature. Chemical shifts (ס) are expressed in part per million (ppm), reported as $\mathrm{s}=$ singlet, $d=$ doublet, $\mathrm{t}=$ triplet, $\mathrm{m}=$ multiplet; and referenced to the solvent peak of respectively $\mathrm{CDCl}_{3}, \mathrm{CD}_{2} \mathrm{Cl}_{2},\left(\mathrm{CD}_{3}\right)_{2} \mathrm{SO}\left({ }^{13} \mathrm{C} \mathrm{NMR}: \delta=77.23\right.$; 53.84; 39.52 ppm; ${ }^{1} \mathrm{H}$ NMR: $\delta=7.26 ; 5.32 ; 2.50$ ppm). IR spectra were recorded on ThermoNicolet Avatar 330 FT IR on film. Exact mass measurements were obtained on TQ R30-10 HRMS spectrometer by ESI+ ionization and are reported in $\mathrm{m} / \mathrm{z}$ for the major signal.

Experimental procedures and characterization data for new compounds or compounds made by a new method are listed below. For the experimental procedure and characterization data of the remaining compounds see references: Compounds $2^{17}, 3^{6}, 8^{12}, 9^{12}$, $\mathbf{1 0}^{18}, \mathbf{1 1}^{19}$ were reported in literature, PP1a ${ }^{4 a}$ was reported without full characterization. Reagents were purchased as reagent-grade and used without further purification. All anhydrous reactions were carried out in oven dried glassware and under an inert atmosphere of argon. THF and toluene were dried by purification through activated alumina purification columns. Reactions were monitored by analytical TLC on silica gel 60 F254 plates $0.25 \mathrm{~mm}$, and visualized under UV light ( $\lambda=254$ and $354 \mathrm{~nm}$ ). Silica gel (SDS 60 ACC 35-70 $\mathrm{mm}$ ) was used for column chromatography. Abbreviations: 'C: degrees Celsius. DCM: dichloromethane. ESI: electrospray ionization. $\mathrm{Et}_{2} \mathrm{O}$ : diethyl ether. EtOAc: ethyl acetate. Eq: equivalent(s). Et: Ethyl g: gram. h: hour(s). HRMS: High resolutionmass spectrometry. LiHMDS: Lithium bis(trimethylsilyl)amide. IR: infra-red. $\mathrm{M}$ (moles per litre $\left(\mathrm{mol} \mathrm{L}^{-1}\right)$. Me: methyl. MeCN: acetonitrile. $\mathrm{mg}$ : milligram. $\mathrm{MgSO}_{4}$ : Magnesium sulfate. $\min$ : minute(s). $\mathrm{mL}$ (milliliter). mm: millimeter. mmol: millimole. mol: mole. $m / z$ : mass-tocharge ratio. PTSA: paratoluenesulfonic acid.

$\mathrm{N}_{2}$ : nitrogen $(\mathrm{g})$. NBS. $\mathrm{N}$-bromosuccinimide. $\mathrm{Et}_{3} \mathrm{~N}$ : triethylamine. NMR: Nuclear magnetic resonance. nm: nanometer. ppm: parts per millions. r.t.: room temperature. $\mathrm{tBu}$ : tert-butyl. $t \mathrm{BuXPhos} P d \mathrm{G} 1$ : tert-BuXPhos palladium(II) phenethylamine chloride. THF: tetrahydrofuran. TFA: trifluoroacetic acid. TIPS: triisopropylsilane. $\mu \mathrm{L}$ : microliter(s). $\mu \mathrm{m}$ : micrometre(s). $\mu \mathrm{M}$ :micromolar. $\mu \mathrm{mol}$ : micromole(s). UV: ultraviolet.

\section{tert-butyl-2-(3-\{[(tert-butyldimethylsilyl)oxy]methyl\}pyridin-2- yl)acetate (4)}

Compound 3 (2 g, $7.8 \mathrm{mmol}, 1$ eq.) and $t$-butyl acetate $(1.95 \mathrm{~mL}$, $11.7 \mathrm{mmol}, 1.5$ eq.) were dissolved in $20 \mathrm{~mL}$ of toluene. $t$ BuXPhos Pd G1 (107 mg, $0.16 \mathrm{mmol}, 2 \mathrm{~mol} \%$ ) was added under argon at $0{ }^{\circ} \mathrm{C}$. Solution was stirred for $5 \mathrm{~min}$. Then, LiHMDS (1M in toluene, 23.4 $\mathrm{mL}, 3$ eq.) was carefully added to the mixture which was allowed to warm up to rt for $2 \mathrm{~h}$. A saturated aqueous solution of $\mathrm{NH}_{4} \mathrm{Cl}$ was added and the mixture was extracted with EtOAc $(3 \times 50 \mathrm{~mL})$. 
Organic phase was washed with brine, dried over $\mathrm{MgSO}_{4}$ and concentrated. The resulting residue was purified by silica gel chromatography (Cyclohexane/EtOAc: 9:1 to 8:2). Yellow oil, Yield: $61 \%$. ${ }^{1} \mathrm{H}$ NMR $\left(300 \mathrm{MHz}, \mathrm{CDCl}_{3}\right): \delta 8.47\left(\mathrm{~d}, 1 \mathrm{H}, J=4.2 \mathrm{~Hz}, \mathrm{H}_{5}\right), 7.89$ $\left(\mathrm{d}, 1 \mathrm{H}, J=7.3 \mathrm{~Hz}, \mathrm{H}_{3}\right), 7.30\left(\mathrm{~m}, 1 \mathrm{H}, \mathrm{H}_{4}\right), 4.75\left(\mathrm{~s}, 2 \mathrm{H}, \mathrm{H}_{6}\right), 3.90(\mathrm{~s}, 2 \mathrm{H}$ $\mathrm{H}_{13}$ ), 1.45 (s, $\left.9 \mathrm{H}, \mathrm{H}_{16,17,18}\right), 0.95$ (s, 9H, $\left.\mathrm{H}_{9,10,11}\right), 0.12$ (s, $\left.6 \mathrm{H}, \mathrm{H}_{7,8}\right)$ ppm; ${ }^{13} \mathrm{C}\left\{{ }^{1} \mathrm{H}\right\}$ NMR $\left(75 \mathrm{MHz}, \mathrm{CDCl}_{3}\right): \delta 169.3\left(\mathrm{C}_{14}\right), 151.8\left(\mathrm{C}_{1}\right)$, $147.2\left(\mathrm{C}_{5}\right), 135.1\left(\mathrm{C}_{2}\right), 134.4\left(\mathrm{C}_{3}\right), 122.0\left(\mathrm{C}_{4}\right), 80.8\left(\mathrm{C}_{15}\right), 61.7\left(\mathrm{C}_{6}\right)$, $42.2\left(\mathrm{C}_{13}\right), 27.8\left(\mathrm{C}_{16,17,18}\right), 25.6\left(\mathrm{C}_{9,10,11}\right), 18.1\left(\mathrm{C}_{12}\right),-5.5\left(\mathrm{C}_{7,8}\right) \mathrm{ppm}$; IR: 2930, 2857, 1731, 1577, 1391, 1254, 1146, 1076, 837, $777 \mathrm{~cm}^{-1}$; HRMS (ESI): $\mathrm{m} / z$ calcd for $\mathrm{C}_{18} \mathrm{H}_{31} \mathrm{NNaO}_{3} \mathrm{Si}: 360.1965$, found: $360.1976[\mathrm{M}+\mathrm{Na}]^{+}$

\section{General procedure A for the synthesis of compounds $5 \mathrm{~b}$ and 5d-g}

Compound 4 (300 mg, $0.89 \mathrm{mmol}, 1$ eq.) was dissolved in $5 \mathrm{~mL}$ of THF. LiHMDS ( $1 \mathrm{M}$ in toluene, $0.98 \mathrm{~mL}, 1.1$ eq.) was added at $0{ }^{\circ} \mathrm{C}$. The mixture was stirred at this temperature for $20 \mathrm{~min}$. The appropriate halogenoalkane (1.1 eq.) was added dropwise and the solution was allowed to warm up to $\mathrm{rt}$ for $20 \mathrm{~h}$. A saturated aqueous solution of $\mathrm{NH}_{4} \mathrm{Cl}$ was added and the mixture was extracted with DCM. Organic phase was washed with brine, dried over $\mathrm{MgSO}_{4}$ and concentrated. The resulting residue was purified by silica gel chromatography (Cyclohexane/EtOAc: 9:1).

\section{tert-butyl-2-(3-\{[(tert-butyldimethylsilyl)oxy]methyl\}pyridin-2- yl)propanoate (5b)}

From compound $\mathbf{4}$ according to general procedure A. Yellow oil, Yield: $89 \%$. ${ }^{1} \mathrm{H}$ NMR $\left(300 \mathrm{MHz}, \mathrm{CDCl}_{3}\right): \delta 8.47(\mathrm{~d}, 1 \mathrm{H}, J=3.8 \mathrm{~Hz}$, $\left.\mathrm{H}_{5}\right), 7.75\left(\mathrm{~d}, 1 \mathrm{H}, J=7.7 \mathrm{~Hz}, \mathrm{H}_{3}\right), 7.16\left(\mathrm{dd}, 1 \mathrm{H}, J_{1}=7.70, J_{2}=4.9 \mathrm{~Hz}\right.$, $\left.\mathrm{H}_{4}\right), 4.82\left(\mathrm{~d}, 1 \mathrm{H}, J=13.3 \mathrm{~Hz}, \mathrm{H}_{13 \mathrm{a}}\right), 4.75\left(\mathrm{~d}, 1 \mathrm{H}, J=13.5 \mathrm{~Hz}, \mathrm{H}_{13 \mathrm{~b}}\right)$, 3.93 (q, $1 \mathrm{H}, J=6.9 \mathrm{~Hz}, \mathrm{H}_{6}$ ), 1.49 (d, $3 \mathrm{H}, J=7.15 \mathrm{~Hz}, \mathrm{H}_{7}$ ), 1.36 (s, $\left.9 \mathrm{H}, \mathrm{H}_{10,11,12}\right), 0.95$ (s, 9H, $\left.\mathrm{H}_{17,18,19}\right), 0.13$ (s, 3H, $\left.\mathrm{H}_{14 / 15}\right), 0.11$ (s, 3H, $\left.\mathrm{H}_{14 / 15}\right) \mathrm{ppm} ;{ }^{13} \mathrm{C}\left\{{ }^{1} \mathrm{H}\right\} \mathrm{NMR}\left(75 \mathrm{MHz}, \mathrm{CDCl}_{3}\right): \delta 172.5\left(\mathrm{C}_{8}\right), 157.4\left(\mathrm{C}_{1}\right)$, $147.7\left(\mathrm{C}_{5}\right), 134.6\left(\mathrm{C}_{3}\right), 133.9\left(\mathrm{C}_{2}\right), 121.6\left(\mathrm{C}_{4}\right), 80.4\left(\mathrm{C}_{9}\right), 61.8\left(\mathrm{C}_{13}\right)$, $43.8\left(\mathrm{C}_{6}\right), 27.9\left(\mathrm{C}_{10,11,12}\right), 25.8\left(\mathrm{C}_{17,18,19}\right), 18.2\left(\mathrm{C}_{16}\right), 15.9\left(\mathrm{C}_{7}\right),-5.3$ $\left(\mathrm{C}_{14 / 15}\right),-5.3\left(\mathrm{C}_{14 / 15}\right) \mathrm{ppm}$; IR: 2931, 2857, 1736, 1576, 1458, 1367, 1254, 1150, 1063, 836, $777 \mathrm{~cm}^{-1}$; HRMS (ESI): $\mathrm{m} / \mathrm{z}$ calcd for $\mathrm{C}_{19} \mathrm{H}_{33} \mathrm{NNaO}_{3} \mathrm{Si}: 374.2122$, found: $374.2129[\mathrm{M}+\mathrm{Na}]^{+}$

tert-butyl-2-(3-\{[(tert-butyldimethylsilyl)oxy]methyl\}pyridin-2-yl)2-methylpropanoate (5c)

Compound 4 (300 mg, $0.89 \mathrm{mmol}, 1$ eq.) was dissolved in $5 \mathrm{~mL}$ of THF. LiHMDS (1M in toluene, $1.96 \mathrm{~mL}, 2.2$ eq.) was added at $0{ }^{\circ} \mathrm{C}$. The mixture was stirred at this temperature for $20 \mathrm{~min}$. Mel $(166 \mu \mathrm{L}$, $2.67 \mathrm{mmol}, 3$ eq.) was added dropwise and the solution was allowed to warm at $\mathrm{rt}$ for $20 \mathrm{~h}$. A saturated aqueous solution of $\mathrm{NH}_{4} \mathrm{Cl}$ was added and the mixture was extracted with DCM. Organic phase was washed with brine, dried over $\mathrm{MgSO}_{4}$ and concentrated. The resulting residue was purified by silica gel chromatography (Cyclohexane/EtOAc: 9:1). Yellow oil, Yield: 89\%; ${ }^{1} \mathrm{H}$ NMR (300 $\left.\mathrm{MHz}, \mathrm{CDCl}_{3}\right)$ : $\delta 8.45\left(\mathrm{~d}, 1 \mathrm{H}, J=4.4 \mathrm{~Hz}, \mathrm{H}_{5}\right), 7.91(\mathrm{~d}, 1 \mathrm{H}, J=7.5 \mathrm{~Hz}$, $\left.\mathrm{H}_{3}\right), 7.25-7.18\left(\mathrm{~m}, 1 \mathrm{H}, \mathrm{H}_{4}\right), 4.65\left(\mathrm{~s}, 2 \mathrm{H}, \mathrm{H}_{14}\right), 1.58\left(\mathrm{~s}, 6 \mathrm{H}, \mathrm{H}_{7,8}\right), 1.42$ (s, 9H, $\left.\mathrm{H}_{11,12,13}\right), 0.96\left(\mathrm{~s}, 9 \mathrm{H}, \mathrm{H}_{18,19,20}\right), 0.13$ (s, 6H, $\left.\mathrm{H}_{15 / 16}\right) \mathrm{ppm} ;{ }^{13} \mathrm{C}$ $\left\{{ }^{1} \mathrm{H}\right\}$ NMR $\left(75 \mathrm{MHz}, \mathrm{CDCl}_{3}\right): \delta 176.0\left(\mathrm{C}_{9}\right), 158.6\left(\mathrm{C}_{1}\right), 146.3\left(\mathrm{C}_{5}\right)$, $135.1\left(\mathrm{C}_{3}\right), 134.4\left(\mathrm{C}_{2}\right), 121.6\left(\mathrm{C}_{4}\right), 80.4\left(\mathrm{C}_{10}\right), 60.8\left(\mathrm{C}_{14}\right), 49.9\left(\mathrm{C}_{6}\right)$, $27.6\left(C_{11,12,13}\right), 25.8\left(C_{7,8}\right), 25.8\left(C_{18,19,20}\right), 18.1\left(C_{17}\right),-5.4\left(C_{15 / 16}\right)$ ppm; IR: 2930, 2858, 1723, 1569, 1470, 1367, 1255, 1145, 1117, 1068, 839, $776 \mathrm{~cm}^{-1}$; HRMS (ESI): $\mathrm{m} / z$ calcd for $\mathrm{C}_{20} \mathrm{H}_{36} \mathrm{NO}_{3} \mathrm{Si}$ : 366.2459, found: $366.2453[\mathrm{M}+\mathrm{H}]^{+}$ tert-butyl-2-(3-\{[(tert-butyldimethylsilyl)oxy]methyl\}pyridin-2-yl)3-methylbutanoate (5d)

From compound $\mathbf{4}$ according to general procedure A. Yellow oil, Yield: $62 \%$. ${ }^{1} \mathrm{H}$ NMR $\left(300 \mathrm{MHz}, \mathrm{CDCl}_{3}\right): \delta 8.54(\mathrm{~d}, 1 \mathrm{H}, J=3.6 \mathrm{~Hz}$, $\left.\mathrm{H}_{5}\right), 7.80\left(\mathrm{~d}, 1 \mathrm{H}, J=7.5 \mathrm{~Hz}, \mathrm{H}_{3}\right), 7.17\left(\mathrm{dd}, 1 \mathrm{H}, J_{1}=7.7, J_{2}=4.7 \mathrm{~Hz}\right.$, $\left.\mathrm{H}_{4}\right), 4.89\left(\mathrm{~d}, 1 \mathrm{H}, J=13.7 \mathrm{~Hz}, \mathrm{H}_{15 a}\right), 4.81\left(\mathrm{~d}, 1 \mathrm{H}, J=13.7 \mathrm{~Hz}, \mathrm{H}_{15 \mathrm{~b}}\right)$, $3.40\left(\mathrm{~d}, 1 \mathrm{H}, J=10.4 \mathrm{~Hz}, \mathrm{H}_{6}\right), 2.85-2.73\left(\mathrm{~m}, 1 \mathrm{H}, \mathrm{H}_{7}\right), 1.36(\mathrm{~s}, 9 \mathrm{H}$, $\left.\mathrm{H}_{12,13,14}\right), 1.12$ (d, 3H, J = 6.4 Hz, H $\mathrm{H}_{8 / 9}$ ), 0.98 (s, 9H, $\left.\mathrm{H}_{19,20,21}\right), 0.68$ (d, $\left.3 \mathrm{H}, J=6.7 \mathrm{~Hz}, \mathrm{H}_{8 / 9}\right), 0.16\left(\mathrm{~s}, 3 \mathrm{H}, \mathrm{H}_{16 / 17}\right), 0.14\left(\mathrm{~s}, 3 \mathrm{H}, \mathrm{H}_{16 / 17}\right) \mathrm{ppm} ;{ }^{13} \mathrm{C}$ $\left\{{ }^{1} \mathrm{H}\right\} \operatorname{NMR}\left(75 \mathrm{MHz}, \mathrm{CDCl}_{3}\right): \delta 170.9\left(\mathrm{C}_{10}\right), 154.8\left(\mathrm{C}_{1}\right), 147.6\left(\mathrm{C}_{5}\right)$, $135.1\left(\mathrm{C}_{2}\right), 134.0\left(\mathrm{C}_{3}\right), 121.4\left(\mathrm{C}_{4}\right), 80.3\left(\mathrm{C}_{11}\right), 61.5\left(\mathrm{C}_{15}\right), 57.1\left(\mathrm{C}_{6}\right)$, $29.4\left(C_{7}\right), 27.8\left(C_{12,13,14}\right), 25.8\left(C_{19,20,21}\right), 21.1\left(C_{8 / 9}\right), 20.1\left(C_{8 / 9}\right), 18.2$ $\left(\mathrm{C}_{18}\right),-5.4\left(\mathrm{C}_{16,17}\right) \mathrm{ppm}$; IR: 2957, 2858, 1739, 1574, 1434, 1367, $1255,1113,1073,837,777 \mathrm{~cm}^{-1}$; HRMS (ESI): $\mathrm{m} / \mathrm{z}$ calcd for $\mathrm{C}_{21} \mathrm{H}_{37} \mathrm{NNaO}_{3} \mathrm{Si}: 402.2435$, found: $402.2447[\mathrm{M}+\mathrm{Na}]^{+}$

\section{tert-butyl-2-(3-\{[(tert-butyldimethylsilyl)oxy]methyl\}pyridin-2-} yl)pent-4-enoate (5e)

From compound $\mathbf{4}$ according to general procedure $\mathbf{A}$. Brown oil, Yield: $89 \%$. ${ }^{1} \mathrm{H}$ NMR $\left(300 \mathrm{MHz}, \mathrm{CDCl}_{3}\right): \delta 8.50(\mathrm{~d}, 1 \mathrm{H}, J=3.4 \mathrm{~Hz}$, $\left.\mathrm{H}_{5}\right), 7.78\left(\mathrm{~d}, 1 \mathrm{H}, J=7.7 \mathrm{~Hz}, \mathrm{H}_{3}\right), 7.19\left(\mathrm{dd}, 1 \mathrm{H}, J_{1}=7.7, J_{2}=4.7 \mathrm{~Hz}\right.$, $\left.\mathrm{H}_{4}\right), 5.75\left(\mathrm{~m}, 1 \mathrm{H}, \mathrm{H}_{8}\right), 5.05\left(\mathrm{~d}, 1 \mathrm{H}, J=17.0 \mathrm{~Hz}, \mathrm{H}_{9 \mathrm{a}}\right), 4.95(\mathrm{~d}, 1 \mathrm{H}, J=$ $\left.10 \mathrm{~Hz}, \mathrm{H}_{9 b}\right), 4.84\left(\mathrm{~d}, 1 \mathrm{H}, J=13.7 \mathrm{~Hz}, \mathrm{H}_{15 \mathrm{a}}\right), 4.79(\mathrm{~d}, 1 \mathrm{H}, J=13.7 \mathrm{~Hz}$, $\left.\mathrm{H}_{15 b}\right), 3.86\left(\mathrm{t}, 1 \mathrm{H}, J=7.3 \mathrm{~Hz}, \mathrm{H}_{6}\right), 2.92\left(\mathrm{~m}, 1 \mathrm{H}, \mathrm{H}_{7 \mathrm{a}}\right), 2.72(\mathrm{~m}, 1 \mathrm{H}$, $\mathrm{H}_{7 \mathrm{~b}}$ ), 1.36 (s, 9H, $\left.\mathrm{H}_{12,13,14}\right), 0.96$ (s, 9H, $\left.\mathrm{H}_{19,20,21}\right), 0.14$ (s, 3H, $\mathrm{H}_{16 / 17}$ ), $0.12\left(\mathrm{~s}, 3 \mathrm{H}, \mathrm{H}_{16 / 17}\right) \mathrm{ppm} ;{ }^{13} \mathrm{C}\left\{{ }^{1} \mathrm{H}\right\} \operatorname{NMR}\left(75 \mathrm{MHz}, \mathrm{CDCl}_{3}\right): \delta 171.0$ $\left(\mathrm{C}_{10}\right), 155.2\left(\mathrm{C}_{1}\right), 147.5\left(\mathrm{C}_{5}\right), 135.8\left(\mathrm{C}_{3}\right), 134.7\left(\mathrm{C}_{2}\right), 134.5\left(\mathrm{C}_{8}\right)$, $121.8\left(\mathrm{C}_{4}\right), 116.4\left(\mathrm{C}_{9}\right), 80.8\left(\mathrm{C}_{11}\right), 61.6\left(\mathrm{C}_{15}\right), 49.2\left(\mathrm{C}_{6}\right), 35.0\left(\mathrm{C}_{7}\right)$ $27.9\left(C_{12,13,14}\right), 25.8\left(C_{19,20,21}\right), 18.3\left(C_{18}\right),-5.3\left(C_{16,17}\right)$ ppm; IR: 2930 2857, 2362, 1737, 1576, 1436, 1367, 1255, 1148, 1076, 837, 777 $\mathrm{cm}^{-1}$; HRMS (ESI): $\mathrm{m} / z$ calcd for $\mathrm{C}_{21} \mathrm{H}_{36} \mathrm{NO}_{3} \mathrm{Si}$ : 378.2459, found: $378.2468[\mathrm{M}+\mathrm{H}]^{+}$

tert-butyl-2-(3-\{[(tert-butyldimethylsilyl)oxy]methyl\}pyridin-2-yl)3-phenylpropanoate (5f)

From compound 4 according to general procedure A. Brown oil, Yield: $61 \%$. ${ }^{1} \mathrm{H}$ NMR $\left(300 \mathrm{MHz}, \mathrm{CDCl}_{3}\right): \delta 8.54(\mathrm{~d}, 1 \mathrm{H}, J=4.5 \mathrm{~Hz}$, $\left.\mathrm{H}_{5}\right), 7.70\left(\mathrm{~d}, 1 \mathrm{H}, J=7.5 \mathrm{~Hz}, \mathrm{H}_{3}\right), 7.15(\mathrm{~m}, 4 \mathrm{H}), 7.04(\mathrm{~m}, 2 \mathrm{H}), 4.62(\mathrm{~d}$, $\left.1 \mathrm{H}, J=13.7 \mathrm{~Hz}, \mathrm{H}_{19 \mathrm{a}}\right), 4.31\left(\mathrm{~d}, 1 \mathrm{H}, J=13.7 \mathrm{~Hz}, \mathrm{H}_{19 \mathrm{~b}}\right), 4.02$ (dd, $1 \mathrm{H}$, $\left.J_{1}=8.6 \mathrm{~Hz}, J_{2}=6.6 \mathrm{~Hz}, \mathrm{H}_{6}\right), 3.49\left(\mathrm{dd}, 1 \mathrm{H}, J_{1}=13.5 \mathrm{~Hz}, J_{2}=6.4 \mathrm{~Hz}\right.$, $\mathrm{H}_{7 \mathrm{a}}$ ), $3.26\left(\mathrm{dd}, 1 \mathrm{H}, J_{1}=13.5 \mathrm{~Hz}, J_{2}=8.4 \mathrm{~Hz}, \mathrm{H}_{7 \mathrm{~b}}\right), 1.33(\mathrm{~s}, 9 \mathrm{H}$, $\left.\mathrm{H}_{16,17,18}\right), 0.92\left(\mathrm{~s}, 9 \mathrm{H}, \mathrm{H}_{23,24,25}\right), 0.03\left(\mathrm{~s}, 6 \mathrm{H}, \mathrm{H}_{20,21}\right) \mathrm{ppm} ;{ }^{13} \mathrm{C}\left\{{ }^{1} \mathrm{H}\right\} \mathrm{NMR}$ $\left(75 \mathrm{MHz}, \mathrm{CDCl}_{3}\right)$ : $\delta 171.0\left(\mathrm{C}_{14}\right), 155.1\left(\mathrm{C}_{1}\right), 147.5\left(\mathrm{C}_{5}\right), 139.5\left(\mathrm{C}_{8}\right)$, $134.9\left(\mathrm{C}_{2}\right), 134.0\left(\mathrm{C}_{3}\right), 128.9\left(\mathrm{C}_{9,13}\right), 128.0\left(\mathrm{C}_{10,12}\right), 126.0\left(\mathrm{C}_{11}\right), 121.7$ $\left(\mathrm{C}_{4}\right), 80.7\left(\mathrm{C}_{15}\right), 61.2\left(\mathrm{C}_{19}\right), 51.1\left(\mathrm{C}_{6}\right), 37.1\left(\mathrm{C}_{7}\right), 27.8\left(\mathrm{C}_{16,17,18}\right), 25.8$ $\left(\mathrm{C}_{23,24,25}\right), 18.2\left(\mathrm{C}_{22}\right),-5.4\left(\mathrm{C}_{20,21}\right) \mathrm{ppm}$; IR: 2955, 2857, 1736, 1576, $1435,1391,1255,1143,837,777,700 \mathrm{~cm}^{-1}$; HRMS (ESI): $\mathrm{m} / z$ calcd for $\mathrm{C}_{25} \mathrm{H}_{37} \mathrm{NNaO}_{3} \mathrm{Si}: 450.2435$, found: $450.2434[\mathrm{M}+\mathrm{Na}]^{+}$

\section{tert-butyl-2-(3-\{[(tert-butyldimethylsilyl)oxy]methyl\}pyridin-2- yl)pent-4-ynoate $(5 \mathrm{~g})$}

From compound $\mathbf{4}$ according to general procedure A. Brown oil, Yield: 59\%. ${ }^{1} \mathrm{H}$ NMR (300 MHz, CDCl $)$ : $\delta 8.49\left(\mathrm{~d}, 1 \mathrm{H}, J=4.0 \mathrm{~Hz}, \mathrm{H}_{5}\right)$, $7.82\left(\mathrm{~d}, 1 \mathrm{H}, J=7.7 \mathrm{~Hz}, \mathrm{H}_{3}\right), 7.21\left(\mathrm{dd}, 1 \mathrm{H}, J_{1}=7.7, J_{2}=4.7 \mathrm{~Hz}, \mathrm{H}_{4}\right)$, $4.94\left(\mathrm{~d}, 1 \mathrm{H}, J=13.7 \mathrm{~Hz}, \mathrm{H}_{15 \mathrm{a}}\right), 4.88\left(\mathrm{~d}, 1 \mathrm{H}, J=13.7 \mathrm{~Hz}, \mathrm{H}_{15 b}\right), 4.03(\mathrm{t}$, $1 \mathrm{H}, J=6.9 \mathrm{~Hz}, \mathrm{H}_{6}$ ), 3.05 (ddd, $1 \mathrm{H}, J_{1}=16.6 \mathrm{~Hz}, J_{2}=6.4 \mathrm{~Hz}, J_{3}=2.3$ $\mathrm{Hz}, \mathrm{H}_{7 \mathrm{a}}$ ), 2.86 (ddd, $1 \mathrm{H}, J_{1}=16.6 \mathrm{~Hz}, J_{2}=8.2 \mathrm{~Hz}, J_{3}=2.3 \mathrm{~Hz}, \mathrm{H}_{7 \mathrm{~b}}$ ), $1.86\left(\mathrm{t}, 1 \mathrm{H}, J=2.3 \mathrm{~Hz}, \mathrm{H}_{9}\right), 1.36\left(\mathrm{~s}, 9 \mathrm{H}, \mathrm{H}_{12,13,14}\right), 0.97(\mathrm{~s}, 9 \mathrm{H}$, $\left.\mathrm{H}_{19,20,21}\right), 0.15$ (s, 3H, $\left.\mathrm{H}_{16 / 17}\right), 0.14$ (s, 3H, $\left.\mathrm{H}_{16 / 17}\right) \mathrm{ppm} ;{ }^{13} \mathrm{C}\left\{{ }^{1} \mathrm{H}\right\} \mathrm{NMR}$ $\left(75 \mathrm{MHz}, \mathrm{CDCl}_{3}\right)$ : $\delta 170.0\left(\mathrm{C}_{10}\right), 154.2\left(\mathrm{C}_{1}\right), 147.6\left(\mathrm{C}_{5}\right), 134.9\left(\mathrm{C}_{2}\right)$, $134.3\left(\mathrm{C}_{3}\right), 122.0\left(\mathrm{C}_{4}\right), 82.1\left(\mathrm{C}_{11}\right), 81.1\left(\mathrm{C}_{8}\right), 69.0\left(\mathrm{C}_{9}\right), 61.6\left(\mathrm{C}_{15}\right)$, 
$48.3\left(\mathrm{C}_{6}\right), 27.8\left(\mathrm{C}_{12,13,14}\right), 25.8\left(\mathrm{C}_{19,20,21}\right), 20.4\left(\mathrm{C}_{7}\right), 18.2\left(\mathrm{C}_{18}\right),-5.4$ $\left(C_{16,17}\right)$ ppm; IR: 3313, 2930, 2857, 1736, 1577, 1438, 1368, 1255, 1147, 1080, 838, $777 \mathrm{~cm}^{-1}$; HRMS (ESI): $\mathrm{m} / \mathrm{z}$ calcd for $\mathrm{C}_{21} \mathrm{H}_{33} \mathrm{NNaO}_{3} \mathrm{Si}: 398.2122$, found: $398.2113[\mathrm{M}+\mathrm{Na}]^{+}$

\section{General procedure B for the synthesis of compounds PP1a-g} The appropriate substrate (4 and $\mathbf{5 b g}$ ) (1 eq.) was dissolved in 10 $\mathrm{mL}$ of toluene. PTSA. $\mathrm{H}_{2} \mathrm{O}$ (2.5 eq.) was added to the mixture which was stirred at rt for 20 h. $40 \mathrm{~mL}$ of a mixture of a saturated aqueous solution of $\mathrm{NaHCO}_{3}$ and EtOAc (1:1) were added to the solution. Organic phase was separated. Aqueous phase was extracted with EtOAc $(2 \times 20 \mathrm{~mL})$. The combined organic phases were washed with brine, dried over $\mathrm{MgSO}_{4}$ and concentrated. The resulting residue was purified by silica gel chromatography (Cyclohexane/EtOAc: 5/5).

\section{$5 \mathrm{H}, 7 \mathrm{H}, 8 \mathrm{H}-$ pyrano[4,3-b]pyridin-7-one PP1a ${ }^{[4 a]}$}

From compound $\mathbf{4}$ according to general procedure $\mathbf{B}$. Brown solid, Yield: $20 \%$. ${ }^{1} \mathrm{H}$ NMR $\left(300 \mathrm{MHz}, \mathrm{CDCl}_{3}\right): \delta 8.60(\mathrm{~d}, 1 \mathrm{H}, J=4.7 \mathrm{~Hz}$, $\left.\mathrm{H}_{5}\right), 7.69\left(\mathrm{~d}, 1 \mathrm{H}, J=7.5 \mathrm{~Hz}, \mathrm{H}_{3}\right), 7.38\left(\mathrm{dd}, 1 \mathrm{H}, J_{1}=7.5, J_{2}=5.14 \mathrm{~Hz}\right.$, $\left.\mathrm{H}_{4}\right), 5.39\left(\mathrm{~s}, 2 \mathrm{H}, \mathrm{H}_{8}\right), 4.07\left(\mathrm{~s}, 2 \mathrm{H}, \mathrm{H}_{6}\right) \mathrm{ppm} ;{ }^{13} \mathrm{C}\left\{{ }^{1} \mathrm{H}\right\} \mathrm{NMR}(75 \mathrm{MHz}$, $\left.\mathrm{CDCl}_{3}\right)$ : $\delta 169.5\left(\mathrm{C}_{7}\right), 151.0\left(\mathrm{C}_{1}\right), 149.9\left(\mathrm{C}_{5}\right), 132.3\left(\mathrm{C}_{3}\right), 126.2\left(\mathrm{C}_{2}\right)$, $122.3\left(\mathrm{C}_{4}\right), 68.2\left(\mathrm{C}_{8}\right), 38.9\left(\mathrm{C}_{6}\right)$ ppm; IR: 2969, 1732, 1588, 1442, $1391,1247,1213,1151,1057,824 \mathrm{~cm}^{-1}$; HRMS (ESI): $\mathrm{m} / z$ calcd for $\mathrm{C}_{8} \mathrm{H}_{7} \mathrm{NO}_{2} \mathrm{Li}: 156.0632$, found : $156.0629[\mathrm{M}+\mathrm{Li}]^{+}$

\section{8-methyl-5H,7H,8H-pyrano[4,3-b]pyridin-7-one (PP1b)}

From compound $\mathbf{5 b}$ according to general procedure $\mathbf{B}$. Yellow oil, Yield: $55 \% .{ }^{1} \mathrm{H}$ NMR $\left(300 \mathrm{MHz}, \mathrm{CDCl}_{3}\right): \delta 8.61\left(\mathrm{~d}, 1 \mathrm{H}, J=4.7 \mathrm{~Hz}, \mathrm{H}_{5}\right)$ $7.5\left(\mathrm{~d}, 1 \mathrm{H}, J=7.5 \mathrm{~Hz}, \mathrm{H}_{3}\right), 7.27\left(\mathrm{~m}, 1 \mathrm{H}, \mathrm{H}_{4}\right), 5.3(\mathrm{~d}, 1 \mathrm{H}, J=14.4 \mathrm{~Hz}$, $\left.\mathrm{H}_{9 \mathrm{a}}\right), 5.30\left(\mathrm{~d}, 1 \mathrm{H}, J=14.3 \mathrm{~Hz}, \mathrm{H}_{9 b}\right), 3.84\left(\mathrm{q}, 1 \mathrm{H}, J=6.9 \mathrm{~Hz}, \mathrm{H}_{6}\right), 1.73$ (d, $\left.3 \mathrm{H}, J=7.1 \mathrm{~Hz}, \mathrm{H}_{7}\right) \mathrm{ppm} ;{ }^{13} \mathrm{C}\left\{{ }^{1} \mathrm{H}\right\} \mathrm{NMR}\left(75 \mathrm{MHz}, \mathrm{CDCl}_{3}\right): \delta 172.7$ $\left(\mathrm{C}_{8}\right), 154.1\left(\mathrm{C}_{1}\right), 149.5\left(\mathrm{C}_{5}\right), 132.1\left(\mathrm{C}_{3}\right), 126.3\left(\mathrm{C}_{2}\right), 121.9\left(\mathrm{C}_{4}\right), 67.2$ $\left(\mathrm{C}_{9}\right), 42.5\left(\mathrm{C}_{6}\right), 11.9\left(\mathrm{C}_{7}\right)$ ppm; IR: 2994, 2946, 1738, 1595, 1436, 1390, 1240, 1152, 1075, 1008, 804, $743 \mathrm{~cm}^{-1}$; HRMS (ESI): $\mathrm{m} / \mathrm{z}$ calcd for $\mathrm{C}_{9} \mathrm{H}_{9} \mathrm{NNaO}_{2}: 186.0525$, found: $186.0518[\mathrm{M}+\mathrm{Na}]^{+}$

\section{8,8-dimethyl-5H,7H,8H-pyrano[4,3-b]pyridin-7-one (PP1c)}

From compound $\mathbf{5 c}$ according to general procedure $\mathbf{B}$. Beige solid, Yield: $99 \%$. ${ }^{1} \mathrm{H}$ NMR $\left(300 \mathrm{MHz}, \mathrm{CDCl}_{3}\right): \delta 8.62(\mathrm{~d}, 1 \mathrm{H}, J=4.4 \mathrm{~Hz}$, $\left.\mathrm{H}_{5}\right), 7.51\left(\mathrm{~d}, 1 \mathrm{H}, J=7.5 \mathrm{~Hz}, \mathrm{H}_{3}\right), 7.25\left(\mathrm{dd}, 1 \mathrm{H}, J_{1}=7.5 \mathrm{~Hz}, J_{2}=4.7\right.$ $\left.\mathrm{Hz}, \mathrm{H}_{4}\right), 5.40$ (s, 2H, $\left.\mathrm{H}_{10}\right), 1.66$ (s, 6H, $\left.\mathrm{H}_{7,8}\right) \mathrm{ppm} ;{ }^{13} \mathrm{C}\left\{{ }^{1} \mathrm{H}\right\}$ NMR $(75$ $\left.\mathrm{MHz}, \mathrm{CDCl}_{3}\right): \delta 175.0\left(\mathrm{C}_{9}\right), 156.9\left(\mathrm{C}_{1}\right), 149.4\left(\mathrm{C}_{5}\right), 132.1\left(\mathrm{C}_{3}\right), 124.6$ $\left(\mathrm{C}_{2}\right), 121.7\left(\mathrm{C}_{4}\right), 66.9\left(\mathrm{C}_{10}\right), 44.7\left(\mathrm{C}_{6}\right), 23.7\left(\mathrm{C}_{7,8}\right)$ ppm; IR: 3004, $1731,1585,1469,1442,1396,1256,1146,1108,1058,801 \mathrm{~cm}^{-1}$; HRMS (ESI): $\mathrm{m} / z$ calcd for $\mathrm{C}_{10} \mathrm{H}_{11} \mathrm{NNaO}_{2}: 200.682$, found: 200.0675 $[\mathrm{M}+\mathrm{Na}]^{+}$

\section{8-(propan-2-yl)-5H,7H,8H-pyrano[4,3-b]pyridin-7-one (PP1d)}

From compound $\mathbf{5 d}$ according to general procedure B. Yellow oil, Yield: $66 \%$. ${ }^{1} \mathrm{H}$ NMR $\left(300 \mathrm{MHz}, \mathrm{CDCl}_{3}\right): \delta 8.60(\mathrm{~d}, 1 \mathrm{H}, J=4.5 \mathrm{~Hz}$, $\left.\mathrm{H}_{5}\right), 7.53\left(\mathrm{~d}, 1 \mathrm{H}, J=7.7 \mathrm{~Hz}, \mathrm{H}_{3}\right), 7.26\left(\mathrm{~m}, 1 \mathrm{H}, \mathrm{H}_{4}\right), 5.53(\mathrm{~d}, 1 \mathrm{H}, J=$ $14.8 \mathrm{~Hz}, \mathrm{H}_{11 \mathrm{a}}$ ), $5.23\left(\mathrm{~d}, 1 \mathrm{H}, J=14.8 \mathrm{~Hz}, \mathrm{H} 11_{\mathrm{b}}\right.$ ), $3.68(\mathrm{~d}, 1 \mathrm{H}, J=7.3$ $\left.\mathrm{Hz}, \mathrm{H}_{6}\right), 2.45-2.29\left(\mathrm{~m}, 1 \mathrm{H}, \mathrm{H}_{7}\right), 1.13\left(\mathrm{~d}, 3 \mathrm{H}, J=6.7 \mathrm{~Hz}, \mathrm{H}_{8 / 9}\right), 1.07$ (d, $\left.3 \mathrm{H}, J=6.7 \mathrm{~Hz}, \mathrm{H}_{8 / 9}\right) \mathrm{ppm} ;{ }^{13} \mathrm{C}\left\{{ }^{1} \mathrm{H}\right\} \mathrm{NMR}\left(75 \mathrm{MHz}, \mathrm{CDCl}_{3}\right): \delta 171.1$ $\left(\mathrm{C}_{10}\right), 153.8\left(\mathrm{C}_{1}\right), 149.5\left(\mathrm{C}_{5}\right), 132.2\left(\mathrm{C}_{3}\right), 125.7\left(\mathrm{C}_{2}\right), 122.0\left(\mathrm{C}_{4}\right), 67.9$ $\left(\mathrm{C}_{11}\right), 55.5\left(\mathrm{C}_{6}\right), 31.6\left(\mathrm{C}_{7}\right), 20.7\left(\mathrm{C}_{8 / 9}\right), 20.2\left(\mathrm{C}_{8 / 9}\right)$ ppm; IR: 2966, $1741,1587,1444,1389,1242,1183,1039,857 \mathrm{~cm}^{-1}$; HRMS (ESI): $\mathrm{m} / \mathrm{z}$ calcd for $\mathrm{C}_{11} \mathrm{H}_{13} \mathrm{NNaO}_{2}: 214.0838$, found: $214.0840[\mathrm{M}+\mathrm{Na}]^{+}$

8-(prop-2-en-1-yl)-5H,7H,8H-pyrano[4,3-b]pyridin-7-one (PP1e) From compound $\mathbf{5 e}$ according to general procedure B. Brown oil, Yield: $67 \%$. ${ }^{1} \mathrm{H}$ NMR $\left(300 \mathrm{MHz}, \mathrm{CDCl}_{3}\right): \delta 8.61(\mathrm{~d}, 1 \mathrm{H}, J=4.5 \mathrm{~Hz}$,
$\left.\mathrm{H}_{5}\right), 7.55\left(\mathrm{~d}, 1 \mathrm{H}, J=7.5 \mathrm{~Hz}, \mathrm{H}_{3}\right), 7.27\left(\mathrm{~m}, 1 \mathrm{H}, \mathrm{H}_{4}\right), 6.00-5.86(\mathrm{~m}, 1 \mathrm{H}$, $\left.\mathrm{H}_{8}\right), 5.41\left(\mathrm{~d}, 1 \mathrm{H}, J=14.4 \mathrm{~Hz}, \mathrm{H}_{11 \mathrm{a}}\right), 5.30\left(\mathrm{~d}, 1 \mathrm{H}, J=14.4 \mathrm{~Hz}, \mathrm{H}_{11 \mathrm{~b}}\right)$, $5.13\left(\mathrm{~d}, 1 \mathrm{H}, J=18.5 \mathrm{~Hz}, \mathrm{H}_{9 \mathrm{a}}\right), 5.09\left(\mathrm{~d}, 1 \mathrm{H}, J=11.0 \mathrm{~Hz}, \mathrm{H}_{9 \mathrm{~b}}\right), 3.92(\mathrm{t}$, $\left.1 \mathrm{H}, J=6.2 \mathrm{~Hz}, \mathrm{H}_{6}\right), 3.03-2.84\left(\mathrm{~m}, 2 \mathrm{H}, \mathrm{H}_{7}\right) \mathrm{ppm} ;{ }^{13} \mathrm{C}\left\{{ }^{1} \mathrm{H}\right\} \mathrm{NMR}(75$ $\left.\mathrm{MHz}, \mathrm{CDCl}_{3}\right): \delta 171.40\left(\mathrm{C}_{10}\right), 153.0\left(\mathrm{C}_{1}\right), 149.6\left(\mathrm{C}_{5}\right), 134.0\left(\mathrm{C}_{3}\right)$, $132.1\left(\mathrm{C}_{8}\right), 126.0\left(\mathrm{C}_{2}\right), 122.0\left(\mathrm{C}_{4}\right), 117.9\left(\mathrm{C}_{9}\right), 67.5\left(\mathrm{C}_{11}\right), 48.0\left(\mathrm{C}_{6}\right)$, $33.4\left(\mathrm{C}_{7}\right)$ ppm; IR: 3074, 2924, 1743, 1589, 1438, 1387, 1255, 1058, 919, $797 \mathrm{~cm}^{-1}$; HRMS (ESI): $\mathrm{m} / z$ calcd for $\mathrm{C}_{11} \mathrm{H}_{11} \mathrm{NNaO}_{2}: 212.0682$, found: $212.0676[\mathrm{M}+\mathrm{Na}]^{+}$

\section{8-benzyl-5H,7H,8H-pyrano[4,3-b]pyridin-7-one (PP1f)}

From compound $\mathbf{5 f}$ according to general procedure $\mathbf{B}$; Brown solid, Yield: $68 \%$. ${ }^{1} \mathrm{H}$ NMR $\left(300 \mathrm{MHz}, \mathrm{CDCl}_{3}\right): \delta 8.63(\mathrm{~d}, 1 \mathrm{H}, J=4.2 \mathrm{~Hz}$, $\left.\mathrm{H}_{5}\right), 7.34\left(\mathrm{~d}, 1 \mathrm{H}, J=7.5 \mathrm{~Hz}, \mathrm{H}_{3}\right), 7.25-7.11\left(\mathrm{~m}, 4 \mathrm{H}, \mathrm{H}_{4,10,11,12}\right), 6.91$ $\left(\mathrm{dd}, 2 \mathrm{H}, J_{1}=7.7 \mathrm{~Hz}, J_{2}=1.6 \mathrm{~Hz}, \mathrm{H}_{9,13}\right), 4.92(\mathrm{~d}, 1 \mathrm{H}, J=14.6 \mathrm{~Hz}$, $\mathrm{H}_{15 \mathrm{a}}$ ), 4.22-4.13 (m, 2H, $\mathrm{H}_{6,15 \mathrm{~b}}$ ), $3.63\left(\mathrm{dd}, 1 \mathrm{H}, J_{1}=13.39 \mathrm{~Hz}, J_{2}=4.9\right.$ $\mathrm{Hz}, \mathrm{H}_{7 \mathrm{a}}$ ), $3.37\left(\mathrm{dd}, 1 \mathrm{H}, J_{1}=13.3 \mathrm{~Hz}, J_{2}=5.5 \mathrm{~Hz}, \mathrm{H}_{7 \mathrm{~b}}\right) \mathrm{ppm} ;{ }^{13} \mathrm{C}\left\{{ }^{1} \mathrm{H}\right\}$ $\operatorname{NMR}\left(75 \mathrm{MHz}, \mathrm{CDCl}_{3}\right)$ : $\delta 171.8\left(\mathrm{C}_{14}\right), 152 .\left(\mathrm{C}_{1}\right), 149.7\left(\mathrm{C}_{5}\right), 136.9$ $\left(\mathrm{C}_{8}\right), 131.7\left(\mathrm{C}_{3}\right), 129.25\left(\mathrm{C}_{9,13}\right), 128.3\left(\mathrm{C}_{10,12}\right), 127.0\left(\mathrm{C}_{11}\right), 126.6\left(\mathrm{C}_{2}\right)$, $122.1\left(\mathrm{C}_{4}\right), 67.5\left(\mathrm{C}_{15}\right), 49.5\left(\mathrm{C}_{6}\right), 37.9\left(\mathrm{C}_{7}\right)$ ppm; IR: 3028, 1742, 1590, 1496, 1452, 1390, 1250, 1149, 1077, 798, $701 \mathrm{~cm}^{-1}$; HRMS (ESI): $\mathrm{C}_{15} \mathrm{H}_{13} \mathrm{NNaO}_{2}: 262.0838$, found: $262.0849[\mathrm{M}+\mathrm{Na}]^{+}$

\section{8-(prop-2-yn-1-yl)-5H,7H,8H-pyrano[4,3-b]pyridin-7-one (PP1g)}

From compound $\mathbf{5 g}$ according to general procedure $\mathrm{B}$. Brown solid, Yield: $66 \%{ }^{1} \mathrm{H}$ NMR $\left(300 \mathrm{MHz}, \mathrm{CDCl}_{3}\right): \delta 8.65(\mathrm{~d}, 1 \mathrm{H}, J=4.40 \mathrm{~Hz}$, $\left.\mathrm{H}_{5}\right), 7.57\left(\mathrm{~d}, 1 \mathrm{H}, J=7.5 \mathrm{~Hz}, \mathrm{H}_{3}\right), 7.30\left(\mathrm{~m}, 1 \mathrm{H}, \mathrm{H}_{4}\right), 5.47(\mathrm{~d}, 1 \mathrm{H}, J=$ $\left.14.4 \mathrm{~Hz}, \mathrm{H}_{11 \mathrm{a}}\right), 5.35$ (d, $\left.1 \mathrm{H}, J=14.4 \mathrm{~Hz}, \mathrm{H}_{11 \mathrm{~b}}\right), 3.96(\mathrm{t}, 1 \mathrm{H}, J=5.3 \mathrm{~Hz}$, $\mathrm{H}_{6}$ ), 3.29 (ddd, $1 \mathrm{H}, J_{1}=16.8 \mathrm{~Hz}, J_{2}=5.1 \mathrm{~Hz}, J_{3}=2.5 \mathrm{~Hz}, \mathrm{H}_{7 \mathrm{a}}$ ), 3.15 (ddd, $1 \mathrm{H}, J_{1}=16.8 \mathrm{~Hz}, J_{2}=5.50 \mathrm{~Hz}, J_{3}=2.5 \mathrm{~Hz}, \mathrm{H}_{7 \mathrm{~b}}$ ), $1.97(\mathrm{t}, 1 \mathrm{H}, J$ $\left.=2.5 \mathrm{~Hz}, \mathrm{H}_{9}\right) \mathrm{ppm} ;{ }^{13} \mathrm{C}\left\{{ }^{1} \mathrm{H}\right\} \mathrm{NMR}\left(75 \mathrm{MHz}, \mathrm{CDCl}_{3}\right): \delta 170.5\left(\mathrm{C}_{10}\right)$, $151.4\left(\mathrm{C}_{1}\right), 149.6\left(\mathrm{C}_{5}\right), 132.1\left(\mathrm{C}_{4}\right), 126.4\left(\mathrm{C}_{2}\right), 122.3\left(\mathrm{C}_{4}\right), 81.1\left(\mathrm{C}_{8}\right)$, $69.8\left(C_{9}\right), 67.6\left(C_{11}\right), 46.4\left(C_{6}\right), 18.06\left(C_{7}\right)$ ppm; IR: 3282, 1746, 1586, 1440, 1386, 1262, 1145, 1063, 1031, 797, $733 \mathrm{~cm}^{-1}$; HRMS (ESI): $\mathrm{m} / \mathrm{z}$ calcd for $\mathrm{C}_{11} \mathrm{H}_{9} \mathrm{NNaO}_{2}: 210.0525$, found: $210.0523[\mathrm{M}+\mathrm{Na}]^{+}$

\section{2-chloro-(3-\{[(tert-}

butyldimethylsilyl)oxy](phenyl)methyl\}pyridine (6)

2-Chloropyridin-3-yl)-phenylmethanol ${ }^{[20]}(18,2 \mathrm{mmol}, 1$ eq.), tertbutyldimethylchlorosilane $(20,2 \mathrm{mmol}, 1.1$ eq.) and imidazole $(36,4$ $\mathrm{mmol}, 2$ eq.) were added to $20 \mathrm{~mL}$ of dry DMF. The reaction mixture was stirred at $\mathrm{rt}$ for $18 \mathrm{~h}$. $200 \mathrm{~mL}$ of $\mathrm{Et}_{2} \mathrm{O}$ were added and the reaction mixture was washed three time with water $(3 \times 100 \mathrm{~mL})$. The combined aqueous layers were extracted with $\mathrm{Et}_{2} \mathrm{O}(100 \mathrm{~mL})$ and the combined organic layers washed with an aqueous saturated solution of $\mathrm{LiCl}$ and brine. The organic layer was dried over $\mathrm{MgSO}_{4}$ and concentrated to afford the title compound. The residue was purified by silica gel chromatography (DCM 100\%). White solid, Yield: 79\%. ${ }^{1} \mathrm{H}$ NMR (300 MHz, DMSO- $\left.d 6\right)$ : $\delta 8.30(\mathrm{~d}, 1 \mathrm{H}, J=4.2 \mathrm{~Hz}$, $\left.\mathrm{H}_{5}\right), 8,03\left(\mathrm{~d}, 1 \mathrm{H}, J_{1}=7,7 \mathrm{~Hz}, J_{2}=1.6 \mathrm{~Hz}, \mathrm{H}_{3}\right), 7.40(\mathrm{~d}, 1 \mathrm{H}, J=7,7 \mathrm{~Hz}$, $\left.\mathrm{H}_{4}\right), 7.27\left(\mathrm{~m}, 5 \mathrm{H}, \mathrm{H}_{8-12}\right), 6,14\left(\mathrm{~s}, 1 \mathrm{H}, \mathrm{H}_{6}\right), 0.91$ (s, $\left.9 \mathrm{H}, \mathrm{H}_{15,16,17}\right), 0.01$ $\left(\mathrm{d}, 6 \mathrm{H}, J=6,4 \mathrm{~Hz}, \mathrm{H}_{13,14}\right) \mathrm{ppm} ;{ }^{13} \mathrm{C}\left\{{ }^{1} \mathrm{H}\right\} \mathrm{NMR}\left(75 \mathrm{MHz}, \mathrm{CDCl}_{3}\right): \delta=$ $148.5\left(\mathrm{C}_{1}\right), 148.3\left(\mathrm{C}_{5}\right), 142.7\left(\mathrm{C}_{2}\right), 139.4\left(\mathrm{C}_{7}\right), 137.2\left(\mathrm{C}_{3}\right), 128.3$ $\left(\mathrm{C}_{8,12}\right), 127.5\left(\mathrm{C}_{10}\right), 126.4\left(\mathrm{C}_{9,11}\right), 122.9\left(\mathrm{C}_{4}\right), 72.3\left(\mathrm{C}_{6}\right), 25.7\left(\mathrm{C}_{15,16,17}\right)$, $18.1\left(\mathrm{C}_{18}\right),-4.9\left(\mathrm{C}_{13,14}\right)$; HRMS (ESI): $\mathrm{m} / \mathrm{z}$ calcd for $\mathrm{C}_{18} \mathrm{H}_{25} \mathrm{CINOSi}$ : 334.1388, found: $334.1389[\mathrm{M}+\mathrm{H}]^{+}$

\section{General procedure $\mathbf{C}$ for the synthesis of compounds $7 \mathrm{a}-7 \mathrm{e}$}

$\mathrm{NaH}(60 \%$ in oil, $17 \mathrm{mmol})$ was added portionwise to a solution of compound 3 or $6(3.4 \mathrm{mmol})$ in THF $(10 \mathrm{~mL})$ at room temperature. The corresponding arylacetonitrile $(4.12 \mathrm{mmol})$ was added to the mixture and the reaction mixture was stirred à $70^{\circ} \mathrm{C}$ for $12 \mathrm{~h}$. Water 
$(20 \mathrm{~mL})$ was added slowly to stop the reaction. EtOAc $(20 \mathrm{~mL})$ was added and the two layers were separated. The aqueous layer was extracted three times with EtOAc $(20 \mathrm{~mL})$. The combined organic phases were washed with brine $(20 \mathrm{~mL})$, dried over $\mathrm{MgSO}_{4}$, filtered and concentrated. The resulting residue was purified by silica gel chromatography to afford the pure product.

\section{2-(3-\{[(tert-butyldimethylsilyl)oxy]methyl\}pyridin-2-yl)-2-}

phenylacetonitrile (7a) From compound $\mathbf{3}$ and phenylacetonitrile according to general procedure $\mathbf{C}$. The residue was purified by silica gel chromatography (Cyclohexane/Ether: $8 / 2,7 / 3$ to $5 / 5$ ). Yellow oil, $69 \%$ yield. ${ }^{1} \mathrm{H}$ NMR $\left(400 \mathrm{MHz}, \mathrm{CDCl}_{3}\right): \delta 8.60(\mathrm{dd}, 1 \mathrm{H}, J$ $\left.=4.6 \mathrm{~Hz}, J=1.2 \mathrm{~Hz}, \mathrm{H}_{5}\right), 7.76\left(\mathrm{~d}, 1 \mathrm{H}, J=7.7 \mathrm{~Hz}, \mathrm{H}_{3}\right), 7.42-7.28(\mathrm{~m}$,

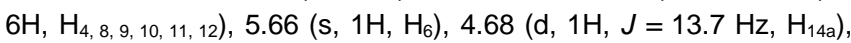
$4.61\left(\mathrm{~d}, 1 \mathrm{H}, J=13.7 \mathrm{~Hz}, \mathrm{H}_{14 \mathrm{~b}}\right), 0.91\left(\mathrm{~s}, 9 \mathrm{H}, \mathrm{H}_{18,19,20}\right), 0.05$ (s, $6 \mathrm{H}$, $\left.\mathrm{H}_{15,16}\right)$, ppm; ${ }^{13} \mathrm{C}\left\{{ }^{1} \mathrm{H}\right\} \mathrm{NMR}\left(75 \mathrm{MHz}, \mathrm{CDCl}_{3}\right): \delta=152.2\left(\mathrm{C}_{1}\right), 148.5$ $\left(C_{5}\right), 136.0\left(C_{3}\right), 134.2\left(C_{2}\right), 134.0\left(C_{7}\right), 129.0\left(C_{8,12}\right), 128.3\left(C_{10}\right)$, $127.8\left(\mathrm{C}_{9,11}\right), 123.3\left(\mathrm{C}_{4}\right), 118.6\left(\mathrm{C}_{13}\right), 61.7\left(\mathrm{C}_{14}\right), 42.3\left(\mathrm{C}_{6}\right), 25.8$ $\left(\mathrm{C}_{18,19,20}\right), 18.2\left(\mathrm{C}_{17}\right),-5.45\left(\mathrm{C}_{15,16}\right)$ ppm; IR: 2954, 2857, 2250, 1576, 1435, 1257, 1117, 1076-837 $\mathrm{cm}^{-1}$; HRMS (ESI): $\mathrm{m} / \mathrm{z}$ calcd for $\mathrm{C}_{20} \mathrm{H}_{26} \mathrm{~N}_{2} \mathrm{NaOSi}$ : 361.1707, found: $361.1694[\mathrm{M}+\mathrm{Na}]^{+}$

\section{2-(4-bromophenyl)-2-(3-\{[(tert-}

butyldimethylsilyl)oxy]methyl\}pyridin-2- yl)acetonitrile (7b)

From compound 3 and 4-bromophenylacetonitrile according to general procedure $\mathbf{C}$. The residue was purified by silica gel chromatography (Cyclohexane/ $\mathrm{Et}_{2} \mathrm{O}: 8 / 2,7 / 3$ to $5 / 5$ ). Yellow oil, 63 $\%$ yield. ${ }^{1} \mathrm{H}$ NMR $\left(400 \mathrm{MHz}, \mathrm{CDCl}_{3}\right): \delta 8.57(\mathrm{~d}, 1 \mathrm{H}, J=4.6 \mathrm{~Hz}, J=$ $\left.1.8 \mathrm{~Hz}, \mathrm{H}_{1}\right), 7.73\left(\mathrm{~d}, 1 \mathrm{H} \mathrm{J}=7.5 \mathrm{~Hz}, \mathrm{H}_{3}\right), 7.49(\mathrm{~d}, 2 \mathrm{H}, J=7.5 \mathrm{~Hz}$, $\left.\mathrm{H}_{18,19}\right), 7.29-7.27\left(\mathrm{~m}, 3 \mathrm{H}, \mathrm{H}_{16,17,2}\right), 5.64\left(\mathrm{~s}, 1 \mathrm{H}, \mathrm{H}_{13}\right), 4.68(\mathrm{~d}, 1 \mathrm{H}, \mathrm{J}=$ $\left.13.4 \mathrm{~Hz}, \mathrm{H}_{6 \mathrm{a}}\right), 4.63\left(\mathrm{~d}, 1 \mathrm{H}, J=13.3 \mathrm{~Hz}, \mathrm{H}_{6 \mathrm{~b}}\right), 0.90$ (s, $9 \mathrm{H}, \mathrm{H}_{10,11,12}$ ), $0.05\left(\mathrm{~s}, 6 \mathrm{H}, \mathrm{H}_{7,8}\right) \mathrm{ppm} ;{ }^{13} \mathrm{C}\left\{{ }^{1} \mathrm{H}\right\} \mathrm{NMR}\left(75 \mathrm{MHz}, \mathrm{CDCl}_{3}\right): \delta=152.1$ $\left(\mathrm{C}_{5}\right), 148.8\left(\mathrm{C}_{1}\right), 136.4\left(\mathrm{C}_{3}\right), 134.0\left(\mathrm{C}_{20}\right), 133.2\left(\mathrm{C}_{4}\right), 132.1\left(\mathrm{C}_{16,17}\right)$, $129.6\left(\mathrm{C}_{18,19}\right), 123.5\left(\mathrm{C}_{2}\right), 122.5\left(\mathrm{C}_{15}\right), 118.3\left(\mathrm{C}_{14}\right), 62.0\left(\mathrm{C}_{6}\right), 41.4$ $\left(\mathrm{C}_{13}\right), 25.8\left(\mathrm{C}_{10,11,12}\right), 18.28\left(\mathrm{C}_{9}\right),-5.38\left(\mathrm{C}_{7,8}\right) \mathrm{ppm}$; HRMS (ESI): $\mathrm{m} / \mathrm{z}$ calcd for $\mathrm{C}_{20} \mathrm{H}_{25} \mathrm{~N}_{2} \mathrm{NaOSi}: 439.0811$, found: $439.0813[\mathrm{M}+\mathrm{Na}]^{+}$

\section{2-(3-\{[(tert-butyldimethylsilyl)oxy]methyl\}pyridin-2-yl)-2-(4- methoxyphenyl)acetonitrile (7c)}

From compound 3 and 4-methoxyphenylacetonitrile according to general procedure $\mathbf{C}$. The residue was purified by silica gel chromatography (Cyclohexane/ $\mathrm{Et}_{2} \mathrm{O}: 8 / 2,7 / 3$ to $5 / 5$ ). Yellow oil, 74 $\%$ yield. ${ }^{1} \mathrm{H}$ NMR $\left(400 \mathrm{MHz}, \mathrm{CDCl}_{3}\right): \delta=8.60\left(\mathrm{~d}, 1 \mathrm{H}, J=6.3 \mathrm{~Hz}, \mathrm{H}_{1}\right)$, $7.76\left(\mathrm{~d}, 1 \mathrm{H}, J=8.1 \mathrm{~Hz}, \mathrm{H}_{3}\right), 7.30-7.27\left(\mathrm{~m}, 3 \mathrm{H}, \mathrm{H}_{2,16,17}\right), 6.88(\mathrm{~d}, 2 \mathrm{H}, J$ $\left.=8.1 \mathrm{~Hz}, \mathrm{H}_{18,19}\right), 5.6\left(\mathrm{~s}, 1 \mathrm{H}, \mathrm{H}_{13}\right), 4.64\left(\mathrm{~d}, 1 \mathrm{H}, J=13.5 \mathrm{~Hz}, \mathrm{H}_{6 \mathrm{a}}\right), 4.62$ (d, $\left.1 \mathrm{H}, J=13.8 \mathrm{~Hz}, \mathrm{H}_{6 \mathrm{~b}}\right), 3.80\left(\mathrm{~s}, 3 \mathrm{H}, \mathrm{H}_{21}\right), 0.92\left(\mathrm{~s}, 9 \mathrm{H}, \mathrm{H}_{10,11,12}\right), 0.05$ (s, 6H, $\left.\mathrm{H}_{7,8}\right) \mathrm{ppm} ;{ }^{13} \mathrm{C}\left\{{ }^{1} \mathrm{H}\right\}$ NMR $\left(75 \mathrm{MHz}, \mathrm{CDCl}_{3}\right): \delta=159.7\left(\mathrm{C}_{20}\right)$, $152.6\left(\mathrm{C}_{5}\right), 148.6\left(\mathrm{C}_{1}\right), 136.2\left(\mathrm{C}_{3}\right), 134.27\left(\mathrm{C}_{4}\right), 129.2\left(\mathrm{C}_{16,17}\right), 126.1$ $\left(\mathrm{C}_{15}\right), 123.4\left(\mathrm{C}_{2}\right), 119.1\left(\mathrm{C}_{14}\right), 114.6\left(\mathrm{C}_{18,19}\right), 61.9\left(\mathrm{C}_{6}\right), 55.5\left(\mathrm{C}_{21}\right)$, $41.7\left(\mathrm{C}_{13}\right), 25.9\left(\mathrm{C}_{10,11,12}\right), 18.4\left(\mathrm{C}_{9}\right),-5.1\left(\mathrm{C}_{7,8}\right)$ ppm; HRMS (ESI): $\mathrm{m} / \mathrm{z}$ calcd for $\mathrm{C}_{21} \mathrm{H}_{28} \mathrm{~N}_{2} \mathrm{NaO}_{2} \mathrm{Si}$ : 391.1812, found: $391.1814[\mathrm{M}+\mathrm{Na}]^{+}$

\section{2-(3-\{[(tert-butyldimethylsilyl)oxy]methyl\}pyridin-2-yl)-2- (pyridine-2-yl)acetonitrile (7d)}

From compound $\mathbf{3}$ and 2-pyridylacetonitrile according to general procedure $\mathbf{C}$. The residue was purified by silica gel chromatography (Cyclohexane/ $\mathrm{Et}_{2} \mathrm{O}: 8 / 2,7 / 3$ to $5 / 5$ ). Purification of the compound led to degradation. So, the crude was used directly in the next step. Yellow oil (impure product, $56 \%$ estimated yield). ${ }^{1} \mathrm{H}$ NMR (400 $\left.\mathrm{MHz}, \mathrm{CDCl}_{3}\right): 8.47$ (d, $\left.1 \mathrm{H}, 5 \mathrm{~Hz}, \mathrm{H}_{5}\right), 8.46\left(\mathrm{~d}, 1 \mathrm{H}, 4 \mathrm{~Hz}, \mathrm{H}_{18}\right), 7.72(\mathrm{~m}$, $\left.1 \mathrm{H}, \mathrm{H}_{3}\right), 7.65\left(\mathrm{~m}, 1 \mathrm{H}, \mathrm{H}_{16}\right), 7.52\left(\mathrm{~d}, 1 \mathrm{H}, J=8 \mathrm{~Hz}, \mathrm{H}_{15}\right), 7.20(\mathrm{~m}, 1 \mathrm{H}$, $\left.\mathrm{H}_{17}\right), 7.15\left(\mathrm{~m}, 1 \mathrm{H}, \mathrm{H}_{4}\right), 5.69\left(\mathrm{~s}, 1 \mathrm{H}, \mathrm{H}_{13}\right), 4.83\left(\mathrm{~d}, 1 \mathrm{H}, J=13 \mathrm{~Hz}, \mathrm{H}_{6 \mathrm{a}}\right)$, $4.76\left(\mathrm{~d}, 1 \mathrm{H}, J=13 \mathrm{~Hz}, \mathrm{H}_{6 \mathrm{~b}}\right), 0.85$ (s, $\left.1 \mathrm{H}, \mathrm{H}_{10,11,12}\right), 0.02\left(\mathrm{~s}, 3 \mathrm{H}, \mathrm{H}_{7}\right)$, $0.00\left(\mathrm{~s}, 3 \mathrm{H}, \mathrm{H}_{8}\right) \mathrm{ppm} ;{ }^{13} \mathrm{C}\left\{{ }^{1} \mathrm{H}\right\} \mathrm{NMR}\left(75 \mathrm{MHz}, \mathrm{CDCl}_{3}\right): \delta=154.5\left(\mathrm{C}_{1}\right)$, $151.4\left(\mathrm{C}_{19}\right), 149.5\left(\mathrm{C}_{5}\right), 148.4\left(\mathrm{C}_{18}\right), 137.3\left(\mathrm{C}_{3}\right), 135.8\left(\mathrm{C}_{16}\right), 135.3$ $\left(\mathrm{C}_{2}\right), 123.4\left(\mathrm{C}_{15}\right), 123.0\left(\mathrm{C}_{17}\right), 122.4\left(\mathrm{C}_{4}\right), 118.2\left(\mathrm{C}_{14}\right), 61.8\left(\mathrm{C}_{6}\right), 44.9$ $\left(\mathrm{C}_{13}\right), 25.8\left(\mathrm{C}_{11,12,13}\right), 18.3\left(\mathrm{C}_{9}\right),-5.3\left(\mathrm{C}_{7,8}\right)$ ppm; HRMS (ESI): $\mathrm{m} / \mathrm{z}$ calcd for $\mathrm{C}_{19} \mathrm{H}_{26} \mathrm{~N}_{3} \mathrm{OSi}: 340.1840$, found: $340.1842[\mathrm{M}+\mathrm{H}]^{+}$

\section{2-(3-\{[(tert-butyldimethylsilyl)oxy](phenyl)methyl\}pyridin-2-yl)-2-} phenylacetonitrile (7e)

From compound 6 and phenylacetonitrile according to general procedure $\mathbf{C}$. The resulting residue was purified by silica gel chromatography (Cyclohexane/EtOAc: 9:1) and trituration with petroleum ether. White solid, Yield: $30 \% .{ }^{1} \mathrm{H}$ NMR $\left(300 \mathrm{MHz}, \mathrm{CDCl}_{3}\right)$ : $\delta 8.70\left(\mathrm{~d}, 1 \mathrm{H}, J=3,9 \mathrm{~Hz}, \mathrm{H}_{1}\right), 8,04\left(\mathrm{~d}, 1 \mathrm{H}, J=7.5 \mathrm{~Hz}, \mathrm{H}_{3}\right), 7.30(\mathrm{~m}$, $\left.9 \mathrm{H}, \mathrm{H}_{16}, \mathrm{H}_{17}, \mathrm{H}_{18}, \mathrm{H}_{19}, \mathrm{H}_{20}, \mathrm{H}_{24}, \mathrm{H}_{25}, \mathrm{H}_{26}, \mathrm{H}_{2}\right), 7,03$ (m, 2H, $\mathrm{H}_{22,23}$ ), 5,82 (s, $\left.1 \mathrm{H}, \mathrm{H}_{6}\right), 5,55$ (s, $\left.1 \mathrm{H}, \mathrm{H}_{13}\right), 0,94$ (s, $\left.9 \mathrm{H}, \mathrm{H}_{10,11,12}\right), 0.00$ (s, $3 \mathrm{H}, \mathrm{H}_{7,8}$ ), $0.09\left(\mathrm{~s}, 3 \mathrm{H}, \mathrm{H}_{7,8}\right) \mathrm{ppm} ;{ }^{13} \mathrm{C}\left\{{ }^{1} \mathrm{H}\right\}$ NMR $\left(75 \mathrm{MHz}, \mathrm{CDCl}_{3}\right): \delta$ 152,3 $\left(\mathrm{C}_{5}\right)$, $148,8\left(C_{1}\right), 142,0\left(C_{4}\right), 136,5\left(C_{3}\right), 134,4\left(C_{21}\right), 128,8-128,8-127,9-$ $126,5-123,0\left(C_{16,17,18,19,20,22,23,24,25,26}\right), 119,1\left(C_{14}\right), 74,1\left(C_{6}\right), 41,4$ $\left(\mathrm{C}_{13}\right), 25,8\left(\mathrm{C}_{10,11,12}\right),-4,8\left(\mathrm{C}_{7,8}\right),-5,0\left(\mathrm{C}_{7,8}\right) \mathrm{ppm}$; HRMS (ESI): $\mathrm{m} / \mathrm{z}$ calcd for $\mathrm{C}_{26} \mathrm{H}_{31} \mathrm{~N}_{2} \mathrm{OSi}$ : 415.2200, found $415.2201[\mathrm{M}+\mathrm{H}+]$

\section{General procedure D for the synthesis of compounds PP1h to PP1I}

Compound 7a-7e (3.25 mmol, 1 eq.) was dissolved in $20 \mathrm{~mL}$ of toluene. PTSA. $\mathrm{H}_{2} \mathrm{O}$ (19.5 mmol, 6 eq.) was added and the mixture was vigorously stirred and refluxed at $120^{\circ} \mathrm{C}$ for $4 \mathrm{~h}$. The reaction mixture was cooled to room temperature and poured into a mixture of a saturated aqueous solution of $\mathrm{NaHCO}_{3}$ and EtOAc (1/1) $(50 \mathrm{~mL}$ $+50 \mathrm{~mL}$ ). Water was added and the layers were separated. The aqueous layer was extracted with EtOAc $(100 \mathrm{~mL})$. The combined organic layers were washed with water $(100 \mathrm{~mL})$, a saturated aqueous solution of $\mathrm{Na}_{2} \mathrm{CO}_{3}(50 \mathrm{~mL})$ and brine $(50 \mathrm{~mL})$. Finally, the organic layer was dried over $\mathrm{MgSO}_{4}$ and concentrated to afford the title compound. The residue was purified by silica gel chromatography.

\section{8-phenyl-5H,7H,8H-pyrano[4,3-b]pyridin-7-one (PP1h)}

From compound $7 \mathrm{a}$ according to general procedure $\mathbf{D}$. The resulting residue was purified by silica gel chromatography (Cyclohexane/EtOAc: 5:5). Yellow oil, Yield: 60\%. ${ }^{1} \mathrm{H}$ NMR (300 $\left.\mathrm{MHz}, \mathrm{CDCl}_{3}\right): \delta 8.68\left(\mathrm{~d}, 1 \mathrm{H}, J=4.5 \mathrm{~Hz}, \mathrm{H}_{5}\right), 7.62(\mathrm{~d}, 1 \mathrm{H}, J=7.5 \mathrm{~Hz}$, $\left.\mathrm{H}_{3}\right), 7.39-7.28\left(\mathrm{~m}, 4 \mathrm{H}, \mathrm{H}_{4,9,10,11}\right), 7.19\left(\mathrm{~d}, 2 \mathrm{H}, J=6.7 \mathrm{~Hz}, \mathrm{H}_{8,12}\right), 5.32$ (s, $\left.1 \mathrm{H}, \mathrm{H}_{6}\right), 5.29\left(\mathrm{~d}, 1 \mathrm{H}, J=14.4 \mathrm{~Hz}, \mathrm{H}_{14 \mathrm{a}}\right), 5.21(\mathrm{~d}, 1 \mathrm{H}, J=14.4 \mathrm{~Hz}$, $\left.\mathrm{H}_{14 \mathrm{~b}}\right)$ ppm. ${ }^{13} \mathrm{C}\left\{{ }^{1} \mathrm{H}\right\} \mathrm{NMR}\left(75 \mathrm{MHz}, \mathrm{CDCl}_{3}\right): \delta 170.1\left(\mathrm{C}_{13}\right), 153.5\left(\mathrm{C}_{1}\right)$, $149.9\left(C_{5}\right), 133.2\left(C_{2}\right), 133.1\left(C_{3}\right), 129.08\left(C_{8,12}\right), 128.0\left(C_{10}\right), 127.5$ $\left(\mathrm{C}_{9,11}\right), 127.0\left(\mathrm{C}_{7}\right), 122.7\left(\mathrm{C}_{4}\right), 67.7\left(\mathrm{C}_{14}\right), 54.3\left(\mathrm{C}_{6}\right)$ ppm; IR: 3060, 2364, 1744, 1539, 1442, 1242, 1039, $761 \mathrm{~cm}^{-1}$; HRMS (ESI): $\mathrm{m} / \mathrm{z}$ calcd for $\mathrm{C}_{14} \mathrm{H}_{11} \mathrm{NNaO}_{2}$ : 248.0677, found: $248.0682[\mathrm{M}+\mathrm{Na}]^{+}$

\section{4-(4-bromophenyl)-3,4-dihydro-1H-2-benzopyran-3-one (PP1i)} From compound $\mathbf{7 b}$ according to general procedure $\mathbf{D}$. The resulting residue was purified by silica gel chromatography (Cyclohexane/EtOAc: 5:5). Yellow oil, $71 \%$ yield. ${ }^{1} \mathrm{H}$ NMR $(400 \mathrm{MHz}$, $\left.\mathrm{CDCl}_{3}\right): \delta 8.49\left(\mathrm{~d}, 1 \mathrm{H}, J=4.1 \mathrm{~Hz}, \mathrm{H}_{1}\right), 7.87\left(\mathrm{~d}, 1 \mathrm{H}, J=7.5 \mathrm{~Hz}, \mathrm{H}_{3}\right)$, $7.56\left(\mathrm{~d}, 2 \mathrm{H}, J=8.7 \mathrm{~Hz}, \mathrm{H}_{10 / 11}\right), 7.42\left(\mathrm{dd}, 1 \mathrm{H}, J_{1}=7.6 \mathrm{~Hz}, J_{2}=4.9 \mathrm{~Hz}\right.$, $\left.\mathrm{H}_{2}\right), 7.13\left(\mathrm{~d}, 2 \mathrm{H}, J=8.7 \mathrm{~Hz}, \mathrm{H}_{12 / 13}\right), 5.52\left(\mathrm{~d}, 1 \mathrm{H}, J=14.6 \mathrm{~Hz}, \mathrm{H}_{6 \mathrm{a}}\right.$ ), $5.42\left(\mathrm{~d}, 1 \mathrm{H}, J=14.3 \mathrm{~Hz}, \mathrm{H}_{6 \mathrm{~b}}\right), 5.41\left(\mathrm{~s}, 1 \mathrm{H}, \mathrm{H}_{8}\right) \mathrm{ppm} ;{ }^{13} \mathrm{C}\left\{{ }^{1} \mathrm{H}\right\} \mathrm{NMR}$ 
$\left(75 \mathrm{MHz}, \mathrm{CDCl}_{3}\right): \delta=169.5\left(\mathrm{C}_{7}\right), 153.0\left(\mathrm{C}_{5}\right), 150.4\left(\mathrm{C}_{1}\right), 132.8\left(\mathrm{C}_{3}\right)$, $132.6\left(\mathrm{C}_{4}\right), 132.1\left(\mathrm{C}_{10 / 11}\right), 129.5\left(\mathrm{C}_{12 / 13}\right), 126.7\left(\mathrm{C}_{9}\right), 122.8\left(\mathrm{C}_{2}\right), 122.2$ $\left(\mathrm{C}_{14}\right), \quad 67.7 \quad\left(\mathrm{C}_{6}\right), \quad 53.9 \quad\left(\mathrm{C}_{8}\right)$ ppm; HRMS (ESI): $\mathrm{m} / \mathrm{z}$ calcd for $\mathrm{C}_{14} \mathrm{H}_{11} \mathrm{BrNO}_{2}: 303.9894$, found: $303.9969[\mathrm{M}+\mathrm{H}]^{+}$

\section{8-(4-methoxyphenyl)-5H,7H,8H-pyrano[4,3-b]pyridin-7-one (PP1j)}

From compound 7c according to general procedure D. The resulting residue was purified by silica gel chromatography (Cyclohexane/EtOAc: 5:5). Yellow oil, $36 \%$ yield. ${ }^{1} \mathrm{H}$ NMR $(400 \mathrm{MHz}$ $\left.\mathrm{CDCl}_{3}\right): \delta=8.65\left(\mathrm{dd}, 1 \mathrm{H}, J_{1}=4.9 \mathrm{~Hz}, J_{2}=1.7 \mathrm{~Hz}, \mathrm{H}_{1}\right), 7.60(\mathrm{dd}, 1 \mathrm{H}$, $\left.J_{1}=8.1, J_{2}=1.2 \mathrm{~Hz}, \mathrm{H}_{3}\right), 7.33\left(\mathrm{dd}, 1 \mathrm{H}, J_{1}=8.4 \mathrm{~Hz}, J_{2}=1.6 \mathrm{~Hz}, \mathrm{H}_{2}\right)$, $7.06\left(\mathrm{~d}, 2 \mathrm{H}, J=8.4 \mathrm{~Hz}, \mathrm{H}_{10,11}\right), 6.86\left(\mathrm{~d}, 2 \mathrm{H}, J=8.2 \mathrm{~Hz}, \mathrm{H}_{12,13}\right), 5.28$ (d, $\left.1 \mathrm{H}, J=14.2 \mathrm{~Hz}, \mathrm{H}_{6 \mathrm{a}}\right), 5.21\left(\mathrm{~s}, 1 \mathrm{H}, \mathrm{H}_{8}\right), 5.18(\mathrm{~d}, 1 \mathrm{H}, J=14.2 \mathrm{~Hz}$, $\left.\mathrm{H}_{6 b}\right), 3.77\left(\mathrm{~s}, 3 \mathrm{H}, \mathrm{H}_{15}\right) \mathrm{ppm} ;{ }^{13} \mathrm{C}\left\{{ }^{1} \mathrm{H}\right\}$ NMR $\left(75 \mathrm{MHz}, \mathrm{CDCl}_{3}\right): 171.0$ $\left(C_{7}\right), 159.7\left(C_{5}\right), 154.5\left(C_{14}\right), 150.7\left(C_{1}\right), 133.1\left(C_{3}\right), 129.2\left(C_{10 / 11}\right)$, $127.2\left(\mathrm{C}_{9}\right), 125.7\left(\mathrm{C}_{4}\right), 123.0\left(\mathrm{C}_{2}\right), 114.9\left(\mathrm{C}_{12 / 13}\right), 68.2\left(\mathrm{C}_{6}\right), 55.7\left(\mathrm{C}_{15}\right)$ $54.3\left(\mathrm{C}_{8}\right) \mathrm{ppm}$; HRMS (ESI): $\mathrm{m} / z$ calcd for $\mathrm{C}_{15} \mathrm{H}_{13} \mathrm{NNaO}_{3}: 278.0789$, found: $278.0788[\mathrm{M}+\mathrm{Na}]^{+}$

\section{5,8-diphenyl-5H, 7H, 8H-pyrano[4,3-b]pyridin-7-one. (PP1I)} From compound $7 \mathrm{e}$ according to general procedure $\mathbf{D}$.

The resulting residue was purified by silica gel chromatography (Cyclohexane/EtOAc: 7:3) and trituration with petroleum ether. Yellow solid, $76 \%$ yield. Mixture of 2 inseparable diasteroisomers $3 / 1 ;{ }^{1} \mathrm{H}$ NMR $\left(400 \mathrm{MHz}, \mathrm{CDCl}_{3}\right.$ ) of the major diasteroisomer: $\delta=8.69$

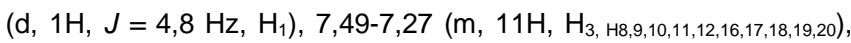
$7,08\left(\mathrm{~d}, 1 \mathrm{H}, J=7,5 \mathrm{~Hz}, \mathrm{H}_{2}\right), 6,23\left(\mathrm{~s}, 1 \mathrm{H}, \mathrm{H}_{6}\right), 5.50\left(\mathrm{~s}, 1 \mathrm{H}, \mathrm{H}_{14}\right) ;{ }^{13} \mathrm{C}$ $\left\{{ }^{1} \mathrm{H}\right\}$ NMR $\left(75 \mathrm{MHz}, \mathrm{CDCl}_{3}\right): 170,1\left(\mathrm{C}_{13}\right), 154,0\left(\mathrm{C}_{5}\right), 150,3\left(\mathrm{C}_{1}\right)$, $135,5\left(C_{4}\right), 134,0\left(C_{3}\right), 133,4\left(C_{7}\right.$ or $\left.C_{15}\right), 131,1\left(C_{15}\right.$ or $\left.C_{7}\right), 129,4-$ 129,1-128,9-128,1-128,0-127,5 ( $\left.\mathrm{C}_{8,9,10,11,12,} 6,17,18,19,20\right), 122,6 \quad\left(\mathrm{C}_{2}\right)$, $79,9\left(\mathrm{C}_{4}\right), 54.9\left(\mathrm{C}_{13}\right)$ ppm; HRMS (ESI): $\mathrm{m} / \mathrm{z}$ calcd for $\mathrm{C}_{20} \mathrm{H}_{16} \mathrm{NO}_{2}$ : 302.1176, found: $302.1176[\mathrm{M}+\mathrm{H}]^{+}$

\section{1-methoxy-3-methylidene-1H,3H-furo[3,4-c]pyridine (12)}

Compound 9 ( $300 \mathrm{mg}, 1.48 \mathrm{mmol}, 1$ eq.) was dissolved in $5 \mathrm{~mL}$ of $\mathrm{MeOH} . \mathrm{K}_{2} \mathrm{CO}_{3}(409 \mathrm{mg}, 2.96 \mathrm{mmol}, 2 \mathrm{eq}$.) was added to the mixture, which was stirred at room temperature for $4 \mathrm{~h}$. Water $(12 \mathrm{~mL})$ was added and the mixture was extracted with DCM $(3 \times 15 \mathrm{~mL})$. Organic phase was washed brine, dried over $\mathrm{MgSO}_{4}$ and concentrated. The resulting residue was purified by silica gel chromatography (Cyclohexane/EtOAc: 7:3 to 6:4) to afford the title compound as a white solid. White solid, Yield: $54 \%$. ${ }^{1} \mathrm{H}$ NMR $\left(300 \mathrm{MHz}, \mathrm{CDCl}_{3}\right)$ : $\delta$ $8.88\left(\mathrm{~s}, 1 \mathrm{H}, \mathrm{H}_{1}\right), 8.65\left(\mathrm{~d}, 1 \mathrm{H}, J=4.9 \mathrm{~Hz}, \mathrm{H}_{5}\right), 7.38(\mathrm{~d}, 1 \mathrm{H}, J=4.9 \mathrm{~Hz}$, $\left.\mathrm{H}_{4}\right), 6.36\left(\mathrm{~s}, 1 \mathrm{H}, \mathrm{H}_{6}\right), 4.78\left(\mathrm{~d}, 1 \mathrm{H}, J=2.5 \mathrm{~Hz}, \mathrm{H}_{9 \mathrm{a}}\right), 4.76(\mathrm{~d}, 1 \mathrm{H}, J=$ $\left.2.5 \mathrm{~Hz}, \mathrm{H}_{9 b}\right), 3.51\left(\mathrm{~s}, 3 \mathrm{H}, \mathrm{H}_{7}\right) \mathrm{ppm} ;{ }^{13} \mathrm{C}\left\{{ }^{1} \mathrm{H}\right\} \mathrm{NMR}\left(75 \mathrm{MHz}, \mathrm{CDCl}_{3}\right)$ : $\delta$ $156.3\left(\mathrm{C}_{8}\right), 149.3\left(\mathrm{C}_{5}\right), 145.5\left(\mathrm{C}_{3}\right), 142.9\left(\mathrm{C}_{1}\right), 129.9\left(\mathrm{C}_{2}\right), 117.5\left(\mathrm{C}_{4}\right)$, $105.5\left(\mathrm{C}_{6}\right), 82.8\left(\mathrm{C}_{9}\right), 55.0\left(\mathrm{C}_{7}\right)$ ppm; IR: 3008, 2941, 1675, 1426, $1373,1340,1204,1101,972,914,811 \mathrm{~cm}^{-1} ;$ HRMS (ESI): $\mathrm{m} / \mathrm{z}$ calcd for $\mathrm{C}_{9} \mathrm{H}_{10} \mathrm{NO}_{2}: 164.0706$, found: $164.0709[\mathrm{M}+\mathrm{H}]^{+}$

\section{(2-ethynylpyridin-3-yl)methanol (13)}

Compound 10 (200 mg, $1.53 \mathrm{mmol}, 1$ eq.) was dissolved in a mixture of $10 \mathrm{~mL}$ of $\mathrm{THF}$ and $1 \mathrm{~mL}$ of water. At $0{ }^{\circ} \mathrm{C}, \mathrm{NaBH}_{4}(58 \mathrm{mg}$, $1.53 \mathrm{mmol}, 1 \mathrm{eq}$.) was added. Mixture was stirred at $0{ }^{\circ} \mathrm{C}$ for $7 \mathrm{~min}$. Water $(10 \mathrm{~mL})$ was added and mixture was extracted with DCM $(3 \mathrm{x}$ $20 \mathrm{~mL}$ ). Organic phase was dried over $\mathrm{MgSO}_{4}$ and concentrated. The title compound was obtained in pure form without any further purification.
Brown solid, Yield: $73 \%$. ${ }^{1} \mathrm{H}$ NMR $\left(300 \mathrm{MHz}\right.$, DMSO- $\left.d_{6}\right): \delta 8.44$ (d, $\left.1 \mathrm{H}, J=4.7 \mathrm{~Hz}, \mathrm{H}_{5}\right), 7.88\left(\mathrm{~d}, 1 \mathrm{H}, J=7.7 \mathrm{~Hz}, \mathrm{H}_{3}\right), 7.4\left(\mathrm{dd}, 1 \mathrm{H}, J_{1}=7.8\right.$ $\left.\mathrm{Hz}, J_{2}=4.77 \mathrm{~Hz}, \mathrm{H}_{4}\right), 5.45(\mathrm{t}, 1 \mathrm{H}, J=5.6 \mathrm{~Hz}, \mathrm{H}), 4.63(\mathrm{~d}, 2 \mathrm{H}, J=5.5$ $\left.\mathrm{Hz}, \mathrm{H}_{6}\right), 4.54\left(\mathrm{~s}, 1 \mathrm{H}, \mathrm{H}_{8}\right) \mathrm{ppm} ;{ }^{13} \mathrm{C}\left\{{ }^{1} \mathrm{H}\right\} \mathrm{NMR}\left(75 \mathrm{MHz}\right.$, DMSO- $\left.d_{6}\right): \delta$ $148.0\left(\mathrm{C}_{5}\right), 140.4\left(\mathrm{C}_{1}\right), 139.0\left(\mathrm{C}_{2}\right), 134.1\left(\mathrm{C}_{3}\right), 123.7\left(\mathrm{C}_{4}\right), 84.5\left(\mathrm{C}_{8}\right)$, $80.6\left(\mathrm{C}_{7}\right), 59.7\left(\mathrm{C}_{6}\right)$ ppm; IR: 3207, 2915, 2104, 1585, 1432, 1048, $695 \mathrm{~cm}^{-1}$; HRMS (ESI): $\mathrm{m} / \mathrm{z}$ calcd for $\mathrm{C}_{8} \mathrm{H}_{8} \mathrm{NO}: 134.0600$, found: $134.0599[\mathrm{M}+\mathrm{H}]^{+}$

\section{(3-ethynylpyridin-4-yl)methanol (14)}

From compound $\mathbf{1 1}$ using the same experimental procedure as for the preparation of 13. Brown solid, Yield: $90 \%$. ${ }^{1} \mathrm{H}$ NMR $(300 \mathrm{MHz}$, $\left.\mathrm{CDCl}_{3}\right)$ : $\delta 8.66\left(\mathrm{~s}, 1 \mathrm{H}, \mathrm{H}_{1}\right), 8.58\left(\mathrm{~d}, 1 \mathrm{H}, J=4.9 \mathrm{~Hz}, \mathrm{H}_{5}\right), 7.52(\mathrm{~d}, 1 \mathrm{H}, J$ $\left.=5.1 \mathrm{~Hz}, \mathrm{H}_{4}\right), 4.89\left(\mathrm{~d}, 1 \mathrm{H}, J=2.5 \mathrm{~Hz}, \mathrm{H}_{6}\right), 3.47\left(\mathrm{~s}, 1 \mathrm{H}, \mathrm{H}_{8}\right), 2.87$ (bt, $1 \mathrm{H}, J=5.3 \mathrm{~Hz}, \mathrm{OH}) \mathrm{ppm} ;{ }^{13} \mathrm{C}\left\{{ }^{1} \mathrm{H}\right\} \mathrm{NMR}\left(75 \mathrm{MHz}, \mathrm{CDCl}_{3}\right): \delta 153.5$ $\left(\mathrm{C}_{3}\right), 151.8\left(\mathrm{C}_{1}\right), 148.6\left(\mathrm{C}_{5}\right), 120.3\left(\mathrm{C}_{4}\right), 116.5\left(\mathrm{C}_{2}\right), 85.5\left(\mathrm{C}_{8}\right), 77.5$ $\left(\mathrm{C}_{7}\right), 61.2\left(\mathrm{C}_{6}\right)$ ppm; IR: 3286, 3166, 2834, 1597, 1404, 1062, 836, $670,615 \mathrm{~cm}^{-1}$; HRMS (ESI): $\mathrm{m} / z$ calcd for $\mathrm{C}_{8} \mathrm{H}_{8} \mathrm{NO}: 134.0600$, found: $134.0597[\mathrm{M}+\mathrm{H}]^{+}$

\section{1-(3-ethynylpyridin-4-yl)ethan-1-ol (15)}

Compound 11 was dissolved in $5 \mathrm{~mL}$ of dry THF. At $-78{ }^{\circ} \mathrm{C}$, a methylmagnesium chloride solution ( $3 \mathrm{M}$ in THF, $330 \mu \mathrm{L}, 0.99 \mathrm{mmol}$, 1.3 eq.) was carefully added. The reaction mixture was allowed to warm at room temperature for $1 \mathrm{~h}$. A saturated aqueous solution of $\mathrm{NH}_{4} \mathrm{Cl}$ was added, followed by a saturated aqueous solution of $\mathrm{NaHCO}_{3}$. EtOAC was added to the mixture and the two layers decanted. The aqueous layer was extracted with EtOAc $(2 \times 20 \mathrm{~mL})$. The combined organic layers were dried over $\mathrm{MgSO}_{4}$ and concentrated. The resulting residue was purified by silica gel chromatography (Cyclohexane/EtOAc: 1:1) to afford the title compound as a white solid. White solid, Yield: $54 \%$. ${ }^{1} \mathrm{H}$ NMR $(300$ $\left.\mathrm{MHz}, \mathrm{CDCl}_{3}\right): \delta 8.67\left(\mathrm{~s}, 1 \mathrm{H}, \mathrm{H}_{1}\right), 8.58\left(\mathrm{~d}, 1 \mathrm{H}, J=5.1 \mathrm{~Hz}, \mathrm{H}_{5}\right), 7.6(\mathrm{~d}$, $\left.1 \mathrm{H}, J=5.1 \mathrm{~Hz}, \mathrm{H}_{4}\right), 5.30$ (q, $1 \mathrm{H}, J=6.4 \mathrm{~Hz}, \mathrm{H}_{6}$ ), $3.51\left(\mathrm{~s}, 1 \mathrm{H}, \mathrm{H}_{9}\right.$ ), $1.54\left(\mathrm{~d}, 3 \mathrm{H}, J=6.6 \mathrm{~Hz}, \mathrm{H}_{7}\right) \mathrm{ppm} ;{ }^{13} \mathrm{C}\left\{{ }^{1} \mathrm{H}\right\} \mathrm{NMR}\left(75 \mathrm{MHz}, \mathrm{CDCl}_{3}\right): \delta$ $157.7\left(\mathrm{C}_{3}\right), 152.5\left(\mathrm{C}_{1}\right), 149.0\left(\mathrm{C}_{5}\right), 119.3\left(\mathrm{C}_{4}\right), 116.2\left(\mathrm{C}_{2}\right), 85.2\left(\mathrm{C}_{9}\right)$, $78.0\left(\mathrm{C}_{8}\right), 66.8\left(\mathrm{C}_{6}\right), 23.7\left(\mathrm{C}_{7}\right) \mathrm{ppm}$; IR: 3210, 3100, 2961, 2103, 1595, 1326, 1230, 1103, 1059, 845, 691, $627 \mathrm{~cm}^{-1}$; HRMS (ESI): $\mathrm{m} / \mathrm{z}$ calcd for $\mathrm{C}_{9} \mathrm{H}_{10} \mathrm{NO}: 148.0757$, found: $148.0755[\mathrm{M}+\mathrm{H}]^{+}$

\section{1-(3-phenylpyridin-4-yl)ethan-1-ol (16)}

Compound 11 (314 mg, $2.39 \mathrm{mmol}$ ) was dissolved in $15 \mathrm{~mL}$ of dry THF. At $-78^{\circ} \mathrm{C}$, a solution of phenylmagnesium chloride (3M in THF, $1,14 \mathrm{~mL}, 5,26 \mathrm{mmol}$ ) was carefully added. The reaction mixture was allowed to warm at room temperature for $1 \mathrm{~h}$. An aqueous saturated solution of $\mathrm{NH} 4 \mathrm{Cl}$ was added, followed by an aqueous saturated solution $\mathrm{NaHCO}$. EtOAc was added $(20 \mathrm{~mL})$ and the two layers decanted. The aqueous layer was extracted with EtOAc $(2 \times 20 \mathrm{~mL})$. The combined organic layers were dried over MgSO4 and concentrated. The resulting residue was purified by silica gel chromatography (Cyclohexane/EtOAc: $7 / 3 \rightarrow 5 / 5$ ) to afford the title compound as a white solid. White solid, $62 \%$ yield. ${ }^{1} \mathrm{H}$ NMR (400 $\left.\mathrm{MHz}, \mathrm{CDCl}_{3}\right): \delta 8.66\left(\mathrm{~s}, 1 \mathrm{H}, \mathrm{H}_{1}\right), 8.59\left(\mathrm{~d}, J=4 \mathrm{~Hz}, 1 \mathrm{H}, \mathrm{H}_{5}\right), 7.74(\mathrm{~d}, J$ $\left.=4 \mathrm{~Hz}, 1 \mathrm{H}, \mathrm{H}_{4}\right), 7.43-7.27\left(\mathrm{~m}, 5 \mathrm{H}, \mathrm{H}_{8-12}\right), 6.24\left(\mathrm{~s}, 1 \mathrm{H}, \mathrm{H}_{6}\right), 3.50(\mathrm{~s}$, $\left.1 \mathrm{H}, \mathrm{H}_{15}\right) ;{ }^{13} \mathrm{C}\left\{{ }^{1} \mathrm{H}\right\} \mathrm{NMR}\left(75 \mathrm{MHz}, \mathrm{CDCl}_{3}\right): \delta 155.3\left(\mathrm{C}_{3}\right), 152.5\left(\mathrm{C}_{1}\right)$, $148.8\left(\mathrm{C}_{5}\right), 141,7\left(\mathrm{C}_{7}\right), 128.4\left(\mathrm{C}_{9,11}\right), 127.9\left(\mathrm{C}_{10}\right), 126.7\left(\mathrm{C}_{8,12}\right), 120.4$ $\left(\mathrm{C}_{4}\right), 117.0\left(\mathrm{C}_{2}\right), 85.5\left(\mathrm{C}_{14}\right), 78,5\left(\mathrm{C}_{13}\right), 72,3\left(\mathrm{C}_{6}\right)$. ppm; HRMS (ESI): $\mathrm{m} / \mathrm{z}$ calcd for $\mathrm{C}_{14} \mathrm{H}_{12} \mathrm{NO}: 210.0913$, found: $210.0914[\mathrm{M}+\mathrm{H}]^{+}$

\{2-[2-(phenylselanyl)ethynyl]pyridin-3-yl\}methanol (17) 
General procedure E: Compound 13 (18.8 mmol, 1 eq.) was dissolved in $30 \mathrm{~mL}$ of DMF. $\mathrm{PhSeBr}$ (18.8 mmol, 1 eq.) and Cul ( $37.6 \mathrm{mmol}, 2$ eq.) were then added to the mixture. The reaction mixture was stirred at room temperature for $2 \mathrm{~h}$. $\mathrm{Et}_{2} \mathrm{O}(200 \mathrm{~mL})$ was added and the mixture was washed with ammonia solution (20\% wt.) $(4 \times 100 \mathrm{~mL})$. The layers were decanted and the aqueous layer extracted with $\mathrm{Et}_{2} \mathrm{O}(1 \times 100 \mathrm{~mL})$. Combined organic layers were washed with water, brine $(1 \times 100 \mathrm{~mL})$ and then dried over $\mathrm{MgSO}_{4}$. After evaporation, the resulting residue was purified by silica gel chromatography (DCM/MeOH: $100 / 0$ to $95 / 5)$ to afford the title compound as a brown solid, Yield: $74 \%$. ${ }^{1} \mathrm{H}$ NMR $(300 \mathrm{MHz}$, DMSO$\left.d_{6}\right): \delta 8.46\left(\mathrm{~d}, 1 \mathrm{H}, J=4.5 \mathrm{~Hz}, \mathrm{H}_{5}\right), 7.89\left(\mathrm{~d}, 1 \mathrm{H}, J=7.7 \mathrm{~Hz}, \mathrm{H}_{3}\right), 7.73-$ $7.67\left(\mathrm{~m}, 2 \mathrm{H}, \mathrm{H}_{10,14}\right), 7.48-7.32\left(\mathrm{~m}, 4 \mathrm{H}, \mathrm{H}_{4,11,12,13}\right), 5.46$ (t, $1 \mathrm{H}, J=5.5$ $\mathrm{Hz}, \mathrm{OH}), 4.65(\mathrm{~d}, 2 \mathrm{H}, J=5.5 \mathrm{~Hz}) \mathrm{ppm} ;{ }^{13} \mathrm{C}\left\{{ }^{1} \mathrm{H}\right\} \mathrm{NMR}(75 \mathrm{MHz}$, DMSO- $\left.d_{6}\right): \delta 148.1\left(C_{5}\right), 139.6,139.5,134.3,129.8,129.1,127.8$ $\left(\mathrm{C}_{9}\right), 127.5,123.3,100.4\left(\mathrm{C}_{8}\right), 75.3\left(\mathrm{C}_{7}\right), 59.9\left(\mathrm{C}_{6}\right)$ ppm; IR: 3224, 3872, 2159, 1577, 1424, 1045, 734, $666 \mathrm{~cm}^{-1}$; HRMS (ESI): $\mathrm{m} / \mathrm{z}$ calcd for $\mathrm{C}_{14} \mathrm{H}_{12} \mathrm{NOSe}: 290.0074$, found: $290.0079[\mathrm{M}+\mathrm{H}]^{+}$

\section{\{3-[2-(phenylselanyl)ethynyl]pyridin-4-yl\}methanol (18)}

From compound $\mathbf{1 4}$ according to general procedure $\mathbf{E}$.

Brown solid, Yield: $78 \%$. ${ }^{1} \mathrm{H}$ NMR $\left(300 \mathrm{MHz}, \mathrm{CDCl}_{3}\right): \delta 8.66(\mathrm{~s}, 1 \mathrm{H}$, $\left.\mathrm{H}_{1}\right), 8.56\left(\mathrm{~d}, 1 \mathrm{H}, J=5.1 \mathrm{~Hz}, \mathrm{H}_{5}\right), 7.60\left(\mathrm{~d}, 2 \mathrm{H}, J=6.7 \mathrm{~Hz}, \mathrm{H}_{10,14}\right), 7.49$ (d, $\left.1 \mathrm{H}, J=5.1 \mathrm{~Hz}, \mathrm{H}_{4}\right), 7.35\left(\mathrm{~m}, 3 \mathrm{H}, \mathrm{H}_{11,12,13}\right), 4.88(\mathrm{~d}, 2 \mathrm{H}, J=4.5 \mathrm{~Hz}$, $\left.\mathrm{H}_{6}\right), 2.26$ (bt, $\left.1 \mathrm{H}, J=5.1 \mathrm{~Hz}, \mathrm{OH}\right) \mathrm{ppm} ;{ }^{13} \mathrm{C}\left\{{ }^{1} \mathrm{H}\right\} \mathrm{NMR}(75 \mathrm{MHz}$, DMSO- $\left.d_{6}\right)$ : $\delta 152.8\left(C_{5}\right), 151.2(C 3), 149.0\left(C_{1}\right), 129.8\left(C_{10,14}\right), 128.9$ $\left(\mathrm{C}_{11,13}\right), 127.4\left(\mathrm{C}_{9}\right), 120.3\left(\mathrm{C}_{4}\right), 116.5\left(\mathrm{C}_{2}\right), 97.1\left(\mathrm{C}_{7}\right), 78.1\left(\mathrm{C}_{8}\right), 60.3$ (C) ppm; IR : 3197, 2161, 1578, 1475, 1439, 1398, 1335, 1233, 1064, 843, 730, $688 \mathrm{~cm}^{-1}$; HRMS (ESI): $\mathrm{m} / \mathrm{z}$ calcd for $\mathrm{C}_{14} \mathrm{H}_{12} \mathrm{NOSe}$ : 290.0079, found: $290.0089[\mathrm{M}+\mathrm{H}]^{+}$

\section{1-\{3-[2-(phenylselanyl)ethynyl]pyridin-4-yl\}ethan-1-ol (19)}

From compound $\mathbf{1 5}$ according to general procedure $\mathrm{E}$. The reaction mixture was stirred at room temperature for $20 \mathrm{~h}$. The resulting residue was purified by silica gel chromatography $(\mathrm{DCM} / \mathrm{MeOH}: 1: 0$ to $97: 3$ ) to afford the title compound. Yellow oil, Yield: $73 \%$. ${ }^{1} \mathrm{H}$ NMR $\left(300 \mathrm{MHz}, \mathrm{CDCl}_{3}\right): \delta 8.64\left(\mathrm{~s}, 1 \mathrm{H}, \mathrm{H}_{1}\right), 8.53\left(\mathrm{~d}, 1 \mathrm{H}, J=4.4 \mathrm{~Hz}, \mathrm{H}_{5}\right)$, 7.63-7.56 (m, 3H), 7.41-7.31 (m, 3H), $5.26\left(\mathrm{q}, 1 \mathrm{H}, J=6.4 \mathrm{~Hz}, \mathrm{H}_{6}\right)$, $1.51\left(\mathrm{~d}, 3 \mathrm{H}, J=6.6 \mathrm{~Hz}, \mathrm{H}_{7}\right) \mathrm{ppm} .{ }^{13} \mathrm{C}\left\{{ }^{1} \mathrm{H}\right\} \mathrm{NMR}\left(75 \mathrm{MHz}\right.$, DMSO- $\left.d_{6}\right)$ : $\delta 157.4\left(C_{3}\right), 151.5\left(C_{1}\right), 149.1\left(C_{5}\right), 129.8\left(C_{11,15}\right), 129.1\left(C_{12,14}\right)$, $128.0\left(\mathrm{C}_{10}\right), 127.5\left(\mathrm{C}_{13}\right), 119.5\left(\mathrm{C}_{4}\right), 116.4\left(\mathrm{C}_{2}\right), 97.3\left(\mathrm{C}_{9}\right), 78.0\left(\mathrm{C}_{8}\right)$ $65.6\left(\mathrm{C}_{6}\right), 24.1\left(\mathrm{C}_{7}\right) \mathrm{ppm}$; IR: 3166, 2972, 2162, 1477, 1099, 731, $687 \mathrm{~cm}^{-1}$; HRMS (ESI): $\mathrm{m} / z$ calcd for $\mathrm{C}_{15} \mathrm{H}_{14} \mathrm{NOSe}: 304.0236$, found: $304.0227[\mathrm{M}+\mathrm{H}]^{+}$

\section{1-\{3-[2-(phenylselanyl)phenyl]pyridin-4-yl\}ethan-1-ol (20)}

From 16 according to the general procedure E: The reaction mixture was stirred at room temperature for $20 \mathrm{~h}$. The resulting residue was purified by silica gel chromatography (DCM/EtOAc 9/1 $\rightarrow 7 / 3$ ) to afford the title compound as a yellow oil, Yield: $55 \%$.

${ }^{1} \mathrm{H}$ NMR $\left(300 \mathrm{MHz}\right.$, DMSO- $\left.d_{6}\right): \delta 8.63\left(\mathrm{~s}, 1 \mathrm{H}, \mathrm{H}_{1}\right), 8.58(\mathrm{~d}, 1 \mathrm{H}, J=4$ $\left.\mathrm{Hz}, \mathrm{H}_{5}\right), 7.68\left(\mathrm{~d}, 1 \mathrm{H}, \mathrm{J}=4 \mathrm{~Hz}, \mathrm{H}_{4}\right), 7.58\left(\mathrm{~m}, 2 \mathrm{H}, \mathrm{H}_{8,12}\right), 7.40-7.22$

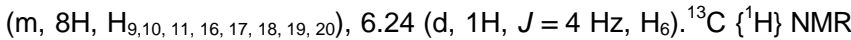
$\left(75 \mathrm{MHz}, \mathrm{CDCl}_{3}\right): \delta 155.2\left(\mathrm{C}_{3}\right), 152.0\left(\mathrm{C}_{1}\right), 149.3\left(\mathrm{C}_{5}\right), 142.8\left(\mathrm{C}_{7}\right)$, 129.8, 129.4, 128.1, 127.5, 127.3, 126.6, $120.4\left(\mathrm{C}_{4}\right), 117.1\left(\mathrm{C}_{2}\right)$, $97.5\left(\mathrm{C}_{14}\right), 78,5\left(\mathrm{C}_{13}\right), 71,4\left(\mathrm{C}_{6}\right)$. ppm; HRMS (ESI): $\mathrm{m} / \mathrm{z}$ calcd for $\mathrm{C}_{20} \mathrm{H}_{15} \mathrm{NNaOSe}$ : 388.0212, found: $388.0204[\mathrm{M}+\mathrm{Na}]^{+}$

\section{H,7H,8H-pyrano[4,3-b]pyridin-7-one (PP1a)}

Procedure F: Compound 17 (2.76 mmol, 1 eq) was dissolved in 40 $\mathrm{mL}$ of toluene. PTSA. monohydrate $(11.04 \mathrm{mmol}, 4$ eq.) was then added and the reaction mixture was refluxed at $120^{\circ} \mathrm{C}$ for $20 \mathrm{~h}$. The reaction mixture was cooled to room temperature and basified with a saturated aqueous solution of $\mathrm{NaHCO}_{3}$. EtOAc was added and the two layers decanted. The aqueous layer was extracted with EtOAc $(2 \times 100 \mathrm{~mL})$. The combined organic layers were dried over $\mathrm{MgSO}_{4}$ and concentrated. The resulting residue was purified by silica gel chromatography ( $\mathrm{DCM} / \mathrm{MeOH}$ : 95:5) to afford the title compound. Beige solid, Yield: $65 \%$. ${ }^{1} \mathrm{H}$ NMR $\left(300 \mathrm{MHz}, \mathrm{CDCl}_{3}\right): \delta 8.60(\mathrm{~d}, 1 \mathrm{H}, J$ $\left.=4.7 \mathrm{~Hz}, \mathrm{H}_{5}\right), 7.69\left(\mathrm{~d}, 1 \mathrm{H}, J=7.5 \mathrm{~Hz}, \mathrm{H}_{3}\right), 7.38\left(\mathrm{dd}, 1 \mathrm{H}, J_{1}=7.5, J_{2}\right.$ $\left.=5.1 \mathrm{~Hz}, \mathrm{H}_{4}\right), 5.39\left(\mathrm{~s}, 2 \mathrm{H}, \mathrm{H}_{8}\right), 4.07\left(\mathrm{~s}, 2 \mathrm{H}, \mathrm{H}_{6}\right) \mathrm{ppm} ;{ }^{13} \mathrm{C}\left\{{ }^{1} \mathrm{H}\right\} \mathrm{NMR}$ (75 MHz, CDCl $)$ : $\delta 169.5\left(\mathrm{C}_{7}\right), 151.0\left(\mathrm{C}_{1}\right), 149.9\left(\mathrm{C}_{5}\right), 132.3\left(\mathrm{C}_{3}\right)$, $126.2\left(\mathrm{C}_{2}\right), 122.3\left(\mathrm{C}_{4}\right), 68.2\left(\mathrm{C}_{8}\right), 38.9\left(\mathrm{C}_{6}\right)$ ppm; IR: 2969, 1732, 1588, 1442, 1391, 1247, 1213, 1151, 1057, $824 \mathrm{~cm}^{-1}$; HRMS (ESI): $\mathrm{m} / \mathrm{z}$ calcd for $\mathrm{C}_{8} \mathrm{H}_{7} \mathrm{NO}_{2} \mathrm{Li}: 156.0632$, found : $156.0629[\mathrm{M}+\mathrm{Li}]^{+}$

\section{1,4-dihydro-3H-pyrano[4,3-c]pyridin-3-one (PP2a)}

From compound $\mathbf{1 8}$ according to general procedure $\mathbf{F}$.

Beige solid, Yield: 39\%. ${ }^{1} \mathrm{H}$ NMR $\left(300 \mathrm{MHz}, \mathrm{CDCl}_{3}\right): \delta 8.58(\mathrm{~d}, 1 \mathrm{H}, J$ $\left.=4.7 \mathrm{~Hz}, \mathrm{H}_{5}\right), 8.50\left(\mathrm{~s}, 1 \mathrm{H}, \mathrm{H}_{1}\right), 7.19\left(\mathrm{~d}, 1 \mathrm{H}, J=4.9 \mathrm{~Hz}, \mathrm{H}_{4}\right), 5.33(\mathrm{~s}$, $\left.2 \mathrm{H}, \mathrm{H}_{6}\right), 3.75\left(\mathrm{~s}, 2 \mathrm{H}, \mathrm{H}_{8}\right) \quad \mathrm{ppm} ;{ }^{13} \mathrm{C}\left\{{ }^{1} \mathrm{H}\right\} \mathrm{NMR}\left(75 \mathrm{MHz}, \mathrm{CDCl}_{3}\right): \delta$ $168.8\left(\mathrm{C}_{7}\right), 148.8\left(\mathrm{C}_{5}\right), 148.0\left(\mathrm{C}_{1}\right), 139.7\left(\mathrm{C}_{3}\right), 126.4\left(\mathrm{C}_{2}\right), 119.0\left(\mathrm{C}_{4}\right)$, $68.8\left(\mathrm{C}_{6}\right), 32.8\left(\mathrm{C}_{8}\right) \mathrm{ppm}$; IR: 2969, 1731, 1392, 1256, 1146, 1032, 829, $707 \mathrm{~cm}^{-1}$; HRMS (ESI): $\mathrm{m} / z$ calcd for $\mathrm{C}_{8} \mathrm{H}_{8} \mathrm{NO}_{2}: 150.0550$, found: $150.0553[\mathrm{M}+\mathrm{H}]^{+}$

\section{1-methyl-1H,3H,4H-pyrano[4,3-c]pyridin-3-one (PP2b)}

From compound 19 according to general procedure $\mathbf{F}$. The reaction mixture was refluxed at $120^{\circ} \mathrm{C}$ for $5 \mathrm{~h}$. The resulting residue was purified by silica gel chromatography $(100 \%$ EtOAc) to afford the title compound. Beige solid, Yield: $63 \%{ }^{1} \mathrm{H}$ NMR $\left(300 \mathrm{MHz}\right.$, DMSO- $\left.d_{6}\right)$ : $\delta 8.54\left(\mathrm{~d}, 1 \mathrm{H}, J=4.9 \mathrm{~Hz}, \mathrm{H}_{5}\right), 8.50\left(\mathrm{~s}, 1 \mathrm{H}, \mathrm{H}_{1}\right), 7.38(\mathrm{~d}, 1 \mathrm{H}, J=4.9$ $\left.\mathrm{Hz}, \mathrm{H}_{4}\right), 5.64\left(\mathrm{q}, 1 \mathrm{H}, J=6.7 \mathrm{~Hz}, \mathrm{H}_{6}\right), 3.92\left(\mathrm{~d}, 1 \mathrm{H}, J=18.5 \mathrm{~Hz}, \mathrm{H}_{8 \mathrm{a}}\right.$ ), $3.85\left(\mathrm{~d}, 1 \mathrm{H}, J=18.5 \mathrm{~Hz}, \mathrm{H}_{8 \mathrm{~b}}\right), 1.65\left(\mathrm{~d}, 3 \mathrm{H}, J=6.6 \mathrm{~Hz}, \mathrm{H}_{7}\right) \mathrm{ppm} ;{ }^{13} \mathrm{C}$ $\left\{{ }^{1} \mathrm{H}\right\}$ NMR $\left(75 \mathrm{MHz}, \mathrm{CDCl}_{3}\right): \delta 168.9\left(\mathrm{C}_{9}\right), 148.9\left(\mathrm{C}_{1}\right), 147.8\left(\mathrm{C}_{5}\right)$, $143.9\left(\mathrm{C}_{3}\right), 126.1\left(\mathrm{C}_{2}\right), 118.0\left(\mathrm{C}_{4}\right), 75.2\left(\mathrm{C}_{6}\right), 32.7\left(\mathrm{C}_{8}\right), 18.7\left(\mathrm{C}_{7}\right)$ ppm; IR: 2950, 1740, 1410, 1340, 1250, 1165, 1077, $651 \mathrm{~cm}^{-1}$; HRMS (ESI): $m / z$ calcd for $\mathrm{C}_{9} \mathrm{H}_{10} \mathrm{NO}_{2}: 164.0706$, found: 164.0706 $[\mathrm{M}+\mathrm{H}]^{+}$

\section{1-phenyl-1H,3H,4H-pyrano[4,3-c]pyridin-3-one (PP2c)}

From compound $\mathbf{2 0}$ according to general procedure $\mathbf{F}$. The reaction mixture was refluxed at $120^{\circ} \mathrm{C}$ for $6 \mathrm{~h}$. The resulting residue was purified by silica gel chromatography (Cyclohexane/ $\mathrm{Et}_{2} \mathrm{O}$ 1/9) to afford the title compound. Beige solid, $37 \%$ yield. ${ }^{1} \mathrm{H} \mathrm{NMR}(400 \mathrm{MHz}$, $\left.\mathrm{CDCl}_{3}\right)$ : $\delta 8.49\left(\mathrm{~m}, 2 \mathrm{H}, \mathrm{H}_{1,5}\right), 7.35\left(\mathrm{~m}, 3 \mathrm{H}, \mathrm{H}_{4}, \mathrm{H}_{9,11}\right), 7.23-7.19(\mathrm{~m}$, $\left.2 \mathrm{H}, \mathrm{H}_{8,12}\right), 6.98\left(\mathrm{~m}, 1 \mathrm{H}, \mathrm{H}_{10}\right), 6.33\left(\mathrm{~s}, 1 \mathrm{H}, \mathrm{H}_{6}\right), 3.72(\mathrm{dd}, J=16 \mathrm{~Hz}, 1 \mathrm{H}$, $\mathrm{H}_{14 \mathrm{a}}$ ), 3.64 (dd, $\left.J=16 \mathrm{~Hz}, 1 \mathrm{H}, \mathrm{H}_{14 \mathrm{~b}}\right) .{ }^{13} \mathrm{C}\left\{{ }^{1} \mathrm{H}\right\} \mathrm{NMR}(101 \mathrm{MHz}$, $\left.\mathrm{CDCl}_{3}\right)$ : $\delta 168.7\left(\mathrm{C}_{13}\right), 148.6\left(\mathrm{C}_{1}\right), 147.8\left(\mathrm{C}_{5}\right), 143.4\left(\mathrm{C}_{3}\right), 135.3\left(\mathrm{C}_{2}\right)$, $129.5\left(C_{10}\right), 129.1\left(C_{8,12}\right), 127.3\left(C_{9,11}\right), 126.7\left(C_{7}\right), 120.3\left(C_{4}\right), 81.0$ $\left(\mathrm{C}_{6}\right), 33.2\left(\mathrm{C}_{14}\right)$. IR: 1737, 1421, 1308, 1237, 1182, 1008, 760, 699 $\mathrm{cm}^{-1}$, HRMS (ESI+): calcd for $\mathrm{C}_{14} \mathrm{H}_{11} \mathrm{NO}_{2}: 225,08$; found $\mathrm{m} / \mathrm{z} 226,08$ $[\mathrm{M}+\mathrm{H}]+$

8-bromo-5H,7H,8H-pyrano[4,3-b]pyridin-7-one (PP1m) Compound PP1a (100 mg, $0.67 \mathrm{mmol}, 1$ eq.) was dissolved in 10 $\mathrm{mL}$ of DCM. NBS (119 mg, $0.67 \mathrm{mmol}, 1$ eq.) was then added and 
the reaction mixture was stirred at room temperature for $10 \mathrm{~min}$. DCM was added and the resulting organic layer was washed twice with an aqueous saturated solution of $\mathrm{NaHCO}_{3}$. The organic layer was dried over $\mathrm{MgSO}_{4}$ and concentrated to afford the title compound in pure form. Brown solid, Yield: $59 \%$. ${ }^{1} \mathrm{H}$ NMR $\left(300 \mathrm{MHz}, \mathrm{CDCl}_{3}\right): \delta$ $8.65\left(\mathrm{~d}, 1 \mathrm{H}, J=6 \mathrm{~Hz}, \mathrm{H}_{5}\right), 7.65\left(\mathrm{~d}, 1 \mathrm{H}, J=9 \mathrm{~Hz}, \mathrm{H}_{3}\right), 7.38$ (dd, $1 \mathrm{H}, J_{1}$ $\left.=9 \mathrm{~Hz}, J_{2}=6 \mathrm{~Hz}, \mathrm{H}_{4}\right), 5.63\left(\mathrm{~d}, 1 \mathrm{H}, J=12 \mathrm{~Hz}, \mathrm{H}_{6 \mathrm{a}}\right), 5.51\left(\mathrm{~s}, 1 \mathrm{H}, \mathrm{H}_{7}\right)$, $5.30\left(\mathrm{~d}, 1 \mathrm{H}, J=12 \mathrm{~Hz}, \mathrm{H}_{6 \mathrm{~b}}\right) \mathrm{ppm} ;{ }^{13} \mathrm{C}\left\{{ }^{1} \mathrm{H}\right\} \mathrm{NMR}\left(100 \mathrm{MHz}, \mathrm{CD}_{3} \mathrm{OD}\right)$ : $\delta 167.4\left(\mathrm{C}_{8}\right), 151.6\left(\mathrm{C}_{1}\right), 151.3\left(\mathrm{C}_{5}\right), 135.7\left(\mathrm{C}_{3}\right), 130.6\left(\mathrm{C}_{2}\right), 126.0$ $\left(\mathrm{C}_{4}\right), 69.4\left(\mathrm{C}_{6}\right), 49.3\left(\mathrm{C}_{7}\right)$ ppm; IR: 2935, 1755, 1432, 1207, 1182, 1023, $779 \mathrm{~cm}^{-1}$; HRMS (ESI): $\mathrm{m} / \mathrm{z}$ calcd for $\mathrm{C}_{8} \mathrm{H}_{6} \mathrm{BrNNaO}_{2}$ : 249.9474, found: $249.9480[\mathrm{M}+\mathrm{Na}]^{+}$

\section{8-bromo-8-phenyl-5H,7H,8H-pyrano[4,3-b]pyridin-7-one (PP1n)} Compound PP1h (100 mg, $0.44 \mathrm{mmol}, 1$ eq.) was dissolved in 10 $\mathrm{mL}$ of DCM. NBS (79 mg, $0.44 \mathrm{mmol}, 1$ eq.) was then added and the reaction mixture was stirred at room temperature for 5 minutes. DCM was added and the resulting organic layer was washed twice with an aqueous saturated solution of $\mathrm{NaHCO}_{3}$. The organic layer was dried over $\mathrm{MgSO}_{4}$ and concentrated to afford the title compound in pure form. Orange solid, Yield: $80 \%$. ${ }^{1} \mathrm{H}$ NMR $\left(300 \mathrm{MHz}, \mathrm{CDCl}_{3}\right)$ : $\delta 8.72$ $\left(\mathrm{d}, 1 \mathrm{H}, J=3 \mathrm{~Hz}, \mathrm{H}_{5}\right), 7.62\left(\mathrm{~d}, 1 \mathrm{H}, J=6 \mathrm{~Hz}, \mathrm{H}_{3}\right), 7.41-7.33(\mathrm{~m}, 6 \mathrm{H}$,

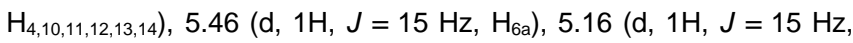
$\left.\mathrm{H}_{6 \mathrm{~b}}\right) \mathrm{ppm} ;{ }^{13} \mathrm{C}\left\{{ }^{1} \mathrm{H}\right\} \mathrm{NMR}\left(75 \mathrm{MHz}, \mathrm{CDCl}_{3}\right): \delta 166.9\left(\mathrm{C}_{8}\right), 152.7\left(\mathrm{C}_{1}\right)$, $150.0\left(\mathrm{C}_{5}\right), 135.7\left(\mathrm{C}_{2}\right), 132.7\left(\mathrm{C}_{3}\right), 128.7\left(\mathrm{C}_{12}\right), 128.3\left(\mathrm{C}_{10,14}\right), 128.3$ $\left(\mathrm{C}_{11,13}\right), 126.5\left(\mathrm{C}_{9}\right), 123.5\left(\mathrm{C}_{4}\right), 67.2\left(\mathrm{C}_{6}\right), 63.4\left(\mathrm{C}_{7}\right) \mathrm{ppm}$; IR : 3092, 1732, 1439, 1388, 1240, 1176, 1049, $754 \mathrm{~cm}^{-1}$; HRMS (ESI): $\mathrm{m} / \mathrm{z}$ calcd for $\mathrm{C}_{14} \mathrm{H}_{10} \mathrm{BrNNaO}_{2}: 325.9787$, found: $325.9797[\mathrm{M}+\mathrm{Na}]^{+}$

\section{8-(4-phenylpiperazin-1-yl)-5H,7H,8H-pyrano[4,3-b]pyridin-7-one (PP10)}

Compound PP1m (130 mg, $0.6 \mathrm{mmol}, 1$ eq.) was dissolved in $5 \mathrm{~mL}$ of acetonitrile. N-phenylpiperazine ( $229 \mu \mathrm{L}, 1.5 \mathrm{mmol}, 2.5 \mathrm{eq}$.) was then added. The reaction mixture was stirred at room temperature for 20 hours. An aqueous saturated solution of $\mathrm{Na}_{2} \mathrm{CO}_{3}$ was added to the mixture, followed by DCM $(20 \mathrm{~mL})$ The two layers were decanted and the aqueous layer extracted with DCM $(2 \times 20 \mathrm{~mL})$. The organic layer was dried over $\mathrm{MgSO}_{4}$ and concentrated. The resulting residue was purified by silica gel chromatography (Cyclohexane/EtOAc: 1:1) to afford the title compound in pure form. White solid, Yield: $22 \% .{ }^{1} \mathrm{H}$ $\operatorname{NMR}\left(300 \mathrm{MHz}, \mathrm{CDCl}_{3}\right): \delta 8.64\left(\mathrm{~d}, 1 \mathrm{H}, J=6 \mathrm{~Hz}, \mathrm{H}_{5}\right), 7.63(\mathrm{~d}, 1 \mathrm{H}, J$ $\left.=6 \mathrm{~Hz}, \mathrm{H}_{3}\right), 7.35\left(\mathrm{~d}, 1 \mathrm{H}, J=6 \mathrm{~Hz}, \mathrm{H}_{4}\right), 7.30-7.20\left(\mathrm{~m}, 2 \mathrm{H}, \mathrm{H}_{15,17}\right)$, 6.94-6.82 (m, 3H, $\left.\mathrm{H}_{14,16,18}\right), 5.92\left(\mathrm{~d}, 1 \mathrm{H}, J=15 \mathrm{~Hz}, \mathrm{H}_{6 \mathrm{a}}\right), 5.14(\mathrm{~d}, 1 \mathrm{H}$, $\left.J=15 \mathrm{~Hz}, \mathrm{H}_{6 \mathrm{~b}}\right), 4.27\left(\mathrm{~s}, 1 \mathrm{H}, \mathrm{H}_{7}\right), 3.23-3.07\left(\mathrm{~m}, 4 \mathrm{H}, \mathrm{H}_{9 / 10 / 11 / 12}\right), 2.94-$ $2.83\left(\mathrm{~m}, 2 \mathrm{H}, \mathrm{H}_{9 / 10 / 11 / 2}\right), 2.70-2.57\left(\mathrm{~m}, 2 \mathrm{H}, \mathrm{H}_{9 / 10 / 11 / 12}\right) \mathrm{ppm} .{ }^{13} \mathrm{C}\left\{{ }^{1} \mathrm{H}\right\}$ $\operatorname{NMR}\left(75 \mathrm{MHz}, \mathrm{CDCl}_{3}\right): \delta 168.8\left(\mathrm{C}_{8}\right), 152.3\left(\mathrm{C}_{1}\right), 150.9\left(\mathrm{C}_{13}\right), 149.6$ $\left(\mathrm{C}_{5}\right), 133.1\left(\mathrm{C}_{3}\right), 129.1\left(\mathrm{C}_{15,17}\right), 128.8\left(\mathrm{C}_{2}\right), 123.4\left(\mathrm{C}_{4}\right), 119.8\left(\mathrm{C}_{16}\right)$ $116.0\left(\mathrm{C}_{14,18}\right), 70.8\left(\mathrm{C}_{6}\right), 68.1\left(\mathrm{C}_{7}\right), 51.2\left(\mathrm{C}_{9 / 10 / 11 / 12}\right), 49.0\left(\mathrm{C}_{9 / 10 / 11 / 12}\right)$ ppm; HRMS (ESI): $\mathrm{m} / z$ calcd for $\mathrm{C}_{18} \mathrm{H}_{20} \mathrm{~N}_{3} \mathrm{O}_{2}: 310.1550$, found: $310.1557[\mathrm{M}+\mathrm{H}]^{+}$

\section{8-phenyl-8-(4-phenylpiperazin-1-yl)-5H,7H,8H-pyrano[4,3- b]pyridin-7-one (PP1p)}

Compound PP1n (100 mg, $0.33 \mathrm{mmol}, 1$ eq.) was dissolved in $5 \mathrm{~mL}$ of acetonitrile. $\mathrm{Et}_{3} \mathrm{~N}(92 \mu \mathrm{L}, 0.66 \mathrm{mmol}, 2$ eq.) and $\mathrm{N}$ phenylpiperazine $(75 \mu \mathrm{L}, 0.49 \mathrm{mmol}, 1.5$ eq.) were successively added. The solution was stirred at room temperature for $20 \mathrm{~h}$. Water $(10 \mathrm{~mL})$ was added, followed by DCM $(30 \mathrm{~mL})$. The two layers were decanted and the aqueous layer extracted with DCM $(2 \times 20 \mathrm{~mL})$. The combined organic layers were washed with an aqueous saturated solution of $\mathrm{Na}_{2} \mathrm{CO}_{3}$, dried over $\mathrm{MgSO}_{4}$ and concentrated.
The resulting residue was purified by silica gel chromatography (Cyclohexane/EtOAc: 8:2 to 6:4) to afford the title compound. Brown oil, Yield: $71 \%$. ${ }^{1} \mathrm{H}$ NMR $\left(400 \mathrm{MHz}, \mathrm{CDCl}_{3}\right)$ : $\delta 8.75(\mathrm{~d}, 1 \mathrm{H}, \mathrm{J}=4 \mathrm{~Hz}$,

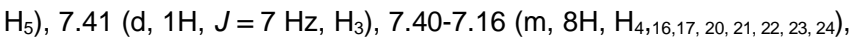
7.00-6.94 (m, 2H, $\left.\mathrm{H}_{14,15}\right), 6.86\left(\mathrm{t}, 1 \mathrm{H}, J=7 \mathrm{~Hz}, \mathrm{H}_{18}\right), 5.09(\mathrm{~d}, 1 \mathrm{H}, J=$ $\left.12 \mathrm{~Hz}, \mathrm{H}_{6 \mathrm{a}}\right), 4.89$ (d, $\left.1 \mathrm{H}, J=12 \mathrm{~Hz}, \mathrm{H}_{6 \mathrm{~b}}\right), 3.35-3.18\left(\mathrm{~m}, 6 \mathrm{H}, \mathrm{H}_{9 / 1 / 11 / 12}\right)$, 3.00-2.91 (m, 2H, $\left.\mathrm{H}_{9 / 10 / 11 / 12}\right) \mathrm{ppm} ;{ }^{13} \mathrm{C}\left\{{ }^{1} \mathrm{H}\right\} \mathrm{NMR}\left(75 \mathrm{MHz}, \mathrm{CDCl}_{3}\right): \delta$ $170.5\left(\mathrm{C}_{7}\right), 155.4\left(\mathrm{C}_{1}\right), 149.8\left(\mathrm{C}_{5}\right), 134.8\left(\mathrm{C}_{13}\right), 132.5\left(\mathrm{C}_{3}\right), 128.8$ $\left(C_{14,15}\right), 128.7\left(C_{16,17,20,21}\right), 128.6\left(C_{22,23,24}\right), 127.7\left(C_{19}\right), 122.2\left(C_{4}\right)$, $116.1\left(\mathrm{C}_{18}\right), 75.2\left(\mathrm{C}_{8}\right), 66.5\left(\mathrm{C}_{6}\right), 47.4\left(\mathrm{C}_{9,10,11,12}\right) \mathrm{ppm}$; HRMS (ESI): $\mathrm{m} / \mathrm{z}$ calcd for $\mathrm{C}_{24} \mathrm{H}_{24} \mathrm{~N}_{3} \mathrm{O}_{2}: 386.1863$, found: $386.1865[\mathrm{M}+\mathrm{H}]^{+}$

\section{8-phenyl-8-(4-methylpiperazin-1-yl)-5H,7H,8H-pyrano[4,3- b]pyridin-7-one (PP1q)}

Compound PP1n (300 mg, 0.99 mmol, 1 eq.) was dissolved in $5 \mathrm{~mL}$ of $\mathrm{DCM} . \mathrm{K}_{2} \mathrm{CO}_{3}(274 \mathrm{mg}, 1.98 \mathrm{mmol}, 2$ eq.) and $\mathrm{N}$-methylpiperazine $(121 \mu \mathrm{L}, 1.09 \mathrm{mmol}, 1.1 \mathrm{eq}$.) were successively added. The solution was stirred at room temperature for $6 \mathrm{~h}$. Water $(10 \mathrm{~mL})$ was added, followed by an aqueous saturated solution of $\mathrm{Na}_{2} \mathrm{CO}_{3}(10 \mathrm{~mL})$ and $\mathrm{DCM}(30 \mathrm{~mL})$. The two layers were decanted and the aqueous layer extracted with DCM $(2 \times 30 \mathrm{~mL})$. The combined organic layers were washed with an aqueous saturated solution of $\mathrm{Na}_{2} \mathrm{CO}_{3}$, dried over $\mathrm{MgSO}_{4}$ and concentrated. The resulting residue was purified by silica gel chromatography (DCM/ NEt 3 : 99/1 to $\mathrm{DCM} / \mathrm{MeOH} / \mathrm{NEt}_{3}$ 97/2/1) to afford the title compound. Yellow oil: $62 \%$. ${ }^{1} \mathrm{H}$ NMR (300 $\left.\mathrm{MHz}, \mathrm{CDCl}_{3}\right): \delta 8.80\left(\mathrm{~d}, 1 \mathrm{H}, J=6 \mathrm{~Hz}, \mathrm{H}_{5}\right), 7.45\left(\mathrm{~d}, 1 \mathrm{H}, J=6 \mathrm{~Hz}, \mathrm{H}_{3}\right)$, 7.41-7.18 (m, 6H, $\left.\mathrm{H}_{4,15,16,17,18,19}\right), 5,05\left(\mathrm{~d}, 1 \mathrm{H}, J=12 \mathrm{~Hz}, \mathrm{H}_{6 \mathrm{a}}\right), 4.84$ (d, $\left.1 \mathrm{H}, J=12 \mathrm{~Hz}, \mathrm{H}_{6 \mathrm{~b}}\right), 3.03\left(\mathrm{~m}, 2 \mathrm{H}, \mathrm{H}_{9}\right), 2,81\left(\mathrm{~m}, 2 \mathrm{H}, \mathrm{H}_{12}\right), 2,50(\mathrm{~m}, 4 \mathrm{H}$, $\left.\mathrm{H}_{10,11}\right), 2,31\left(\mathrm{~s}, 3 \mathrm{H}, \mathrm{H}_{13}\right) \mathrm{ppm} ;{ }^{13} \mathrm{C}\left\{{ }^{1} \mathrm{H}\right\}$ NMR $\left(75 \mathrm{MHz}, \mathrm{CDCl}_{3}\right): \delta$ $170.4\left(\mathrm{C}_{8}\right), 155.7\left(\mathrm{C}_{1}\right), 149.9\left(\mathrm{C}_{5}\right), 135.1\left(\mathrm{C}_{2}\right), 132.4\left(\mathrm{C}_{3}\right), 128.7$ $\left(\mathrm{C}_{15,19}\right), 128.6\left(\mathrm{C}_{16,18}\right), 127.8\left(\mathrm{C}_{14}\right), 122.1\left(\mathrm{C}_{4}\right), 75.2\left(\mathrm{C}_{7}\right), 66.5\left(\mathrm{C}_{6}\right)$, $55.9\left(\mathrm{C}_{9 / 12}\right), 47.3\left(\mathrm{C}_{10 / 11}\right), 46.0\left(\mathrm{C}_{13}\right)$ ppm; HRMS (ESI): calcd for $\mathrm{C}_{19} \mathrm{H}_{22} \mathrm{~N}_{3} \mathrm{O}_{2}: 324.1707$, found: $m / z 324.1707[\mathrm{M}+\mathrm{H}]^{+}$

Keywords: pyridopyridinones • antihistamines • delta-lactone • Pinner reaction $\cdot$ seleno-mediated cyclization

[1] a) J. Taniguchi, J. Pestic. Sci. 1994, 19, 209-219; b) S. Ram, A. K. Saxena, P.C. Jain, G. K. Patanik. J. Chem. Sect. B. 1984, 23, 1261 1267.

[2] a) T.R. Govindachari, N. Viswanathan. Phytochemistry 1972, 11, 3529-3531; b) T. Efferth, Y. J. Fu, Y. G. Zu, G. Schwarz, V. S. Konkimalla, M. Wink. Curr. Med. Chem. 2007, 14, 2024-2032; c) H. Ulukan, P. W. Swaan, Drugs 2002, 62, 2039-2057; d) P. Roy, P. Mitra, K. Ghorai, Tetrahedron. Lett. 2013, 54, 1440-1443; e) B. K. Ghorai, J. W. Herndon, Y-F. Lam, Org. Lett. 2001, 3, 3535-3538; f) S. Arimori, Patent PCT Int. Appl. WO 2017110863, 2017.

[3] a) J. H. Markgrar, S. J. Basta, Synth. Commun. 1972, 3, 139-141; b) K. Shishido, E. Shitara, H. Komatsu, K. Hiyora, K. Fukumoto, T. Kametani, J. Org. Chem. 1986, 51, 3007-3011; c) K. Kobayashi, T. Mannami, M. Kawakita, J. Tokimatsu, H. Konishi. Bull. Chem. Soc. Jpn. 1994, 67, 582-585; d) E. Yoneda, T. Kaneko, S. W. Zhang, S Takahashi, Tetrahedron. Lett. 1998, 39, 5061-5064; e) D. A. Bianchi, N. E. Blanco, N. Carrillo, T. S. Kaufman. J. Agric. Food. Chem. 2004 52, 1923-1927; f) A. Rioz-Martinez, G. de Gonzalo, D. E. Torres Pazmiño, M. W. Fraaije, V. Gotor, J. Org. Chem. 2009, 15, 2526 2532; g) Y. Li, D.-X, Zhu, M.-H. Xu, Chem. Commun. 2013, B, 11659-11661; h) R. Akula, P. J. Guiry, Org. Lett. 2016, 21, 5472 5475; i) G. Albano, M. Morelli, L. A. Aronica, Eur. J. Org. Chem. 2017, 24, 3473-3480; j) M.-Y. Chang, S-M, Cheng, Y.-T. Hsiao. J. Org. Chem. 2019, 84, 11687-11698; k) Y.-Q. Zhang, X.-Q. Zhu, Y. Xu, H.-Z. Bu, J.-L. Wang, T.-Y, Zhai, J.-M. Zhou, L.-W. Ye, Green Chem. 2019, 21, 3023-3028.

[4] a) F. Bohlmann, D. Rahtz, Abhandl. braunschweig. wiss. Ges. 1957 9, 170-172; b) J. Alm, H. U. Jürgens, J. Prakt. Chem. 1991, 333, $177-$ 
180; c) P. Roy, P. Mitra, B. K. Ghorai, Tetrahedron. Lett. 2013, 54, 1440-1443; d) M. -L. Bennasar, T. Roca, E. Zulaica, M. Monerris, Tetrahedron 2004, 60, 6785-6789; e) K. Yabu, S. Masumoto, M. Kanai, D. P. Curran, M. Shibasaki, Tetrahedron Lett. 2002, 43, 2923 2926; f) Y. Sato, T, Iwashige, T. Miyadera. Chem. Pharm. Bull. 1960 8, 427-435.

[5] M. R. Biscoe, S. L. Buchwald, Org. Lett. 2009, 11, 1773-1775.

[6] R. W. Stevens, K. Nakao, K. Kawamura, C. Uchida, S. Fujiwara, Patent PCT Int. Appl. WO 1999005104A1, 1999.

[7] T. Hama, S. Ge, J. F. Hartwig, J. Org. Chem. 2013, 78, 8250-8266.

[8] M. E. Jung, G. Piizzi, Chem. Rev. 2005, 105, 1735-1766.

[9] R. Roger, D. G. Neilson, Chem. Rev. 1961, 61, 179-211.

[10] S. Arseniyadis, K. Kyler, D. S. Watt, Org. React. 1984, 31, 1-71

[11] M. Tiecco, L. Testaferri, A. Temperini, R. Terlizzi, L. Bagnoli, F. Marini, C. Santi, Synlett 2006, 4, 587-589.

[12] A. Numata, Y. Kondo, T. Sakamoto, Synthesis 1999, 306-311.

[13] A. L. Braga, C. C. Silveira, A. Reckziegel, H. Menezes, Tetrahedron. Lett. 1993, 34, 8041-8042.

[14] a) C. Smuda, P. J. Bryce, Curr. Allergy Asthma Rep. 2011, 11, 94 100; b) M. Jutel, M. Akdis, C. A. Akdis, Clin Exp Allergy. 2009, 39, 1786-1800; c) A. J. Ricketti, D. J. Cleri, Allergic Rhinitis. In: Grammer LC, Greenberger PA, editors. Patterson's Allergic Diseases. 7th Edition. Philadelphia: Lippincott Williams \& Wilkins; 2009.

[15] a) W. L. Nelson. "Antihistamines and related antiallergic and antiulcer agents". In Foye's Principles of Medicinal Chemistry (Eds.: W. O Foye, T. L. Lemke, D. A. Williams), Lippincott Williams \& Wilkins, Philadelphia 2008, pp. 1004-1027; b) M. K. Church, D. S. Church, Indian J. Dermatol. 2013, 58, 219-224.

[16] A. M. ter Laak, J. Venhorst, G. M. Donné-Op den Keider, H. Timmerman, J. Med. Chem. 1995, 38, 3351-3360.

[17] E. Buxaderas, D. A. Alonso, C. Najera, Adv. Synth. Catal. 2014, 356, 3415-3421.

[18] P. Roy, P. Mitra, B. K. Ghorai, Tetrahedron Lett. 2013, 54, 14401443.

[19] M. Li, P. Xing, Z. Huang, B. Jiang, Chin. J. Chem. 2013, 31, 49-54.

[20] S. D. Roughley, H. Browne, A. T. Macias, K. Benwell, T. Brooks, J. D'Alessandro, Z. Daniels, S. Dugdale, G. Francis, B. Gibbons, T. Hart, T. Haymes, G. Kennett, S. Lightowler, N. Matassova, H. Mansell, A. Merrett, A. Misra, A. Padfield, R. Parsons, R. Pratt, A. Robertson, H. Simmonite, K. Tan, S. B. Walls, M. Wong. Bioorg. Med. Chem. Lett. 2012, 22, 901-906. 


\section{Entry for the Table of Contents}

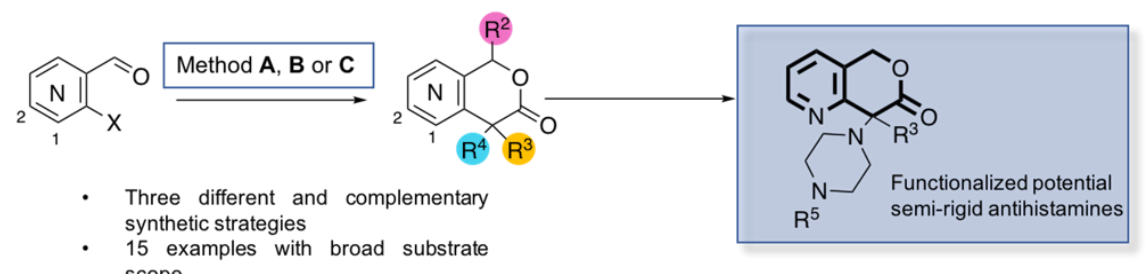

scope

Original pyranopyridinones containing polyfunctionalized delta-lactones ring have been synthesized using three concise and efficient synthetic methodologies. Potential semi-rigid analogs of antihistamines containing a pyranopyridinone scaffold have also been prepared using the outlined synthetic methodologies.

https://twitter.com/ipcm_sorbonne/ 